\title{
Equilibration of the Antarctic Circumpolar Current by Standing Meanders
}

\author{
ANDREW F. THOMPSON \\ California Institute of Technology, Pasadena, California \\ Alberto C. Naveira Garabato \\ National Oceanography Centre, University of Southampton, Southampton, United Kingdom
}

(Manuscript received 24 July 2013, in final form 19 March 2014)

\begin{abstract}
The insensitivity of the Antarctic Circumpolar Current (ACC)'s prominent isopycnal slope to changes in wind stress is thought to stem from the action of mesoscale eddies that counterbalance the wind-driven Ekman overturning - a framework verified in zonally symmetric circumpolar flows. Substantial zonal variations in eddy characteristics suggest that local dynamics may modify this balance along the path of the ACC. Analysis of an eddy-resolving ocean GCM shows that the ACC can be broken into broad regions of weak eddy activity, where surface winds steepen isopycnals, and a small number of standing meanders, across which the isopycnals relax. Meanders are coincident with sites of (i) strong eddy-induced modification of the mean flow and its vertical structure as measured by the divergence of the Eliassen-Palm flux and (ii) enhancement of deep eddy kinetic energy by up to two orders of magnitude over surrounding regions. Within meanders, the vorticity budget shows a balance between the advection of relative vorticity and horizontal divergence, providing a mechanism for the generation of strong vertical velocities and rapid changes in stratification. Temporal fluctuations in these diagnostics are correlated with variability in both the Eliassen-Palm flux and bottom speed, implying a link to dissipative processes at the ocean floor. At larger scales, bottom pressure torque is spatially correlated with the barotropic advection of planetary vorticity, which links to variations in meander structure. From these results, it is proposed that the "flexing" of standing meanders provides an alternative mechanism for reducing the sensitivity of the ACC's baroclinicity to changes in forcing, separate from an ACC-wide change in transient eddy characteristics.
\end{abstract}

\section{Introduction}

A remarkable feature of Southern Ocean circulation models is that the prominent isopycnal slope $s$ that spans the Antarctic Circumpolar Current (ACC) is relatively insensitive to changes in surface forcing. This behavior is explained through the interplay among surface wind forcing, the flow's baroclinicity, and the action of mesoscale eddies. Residual-mean models of the ACC focus on zonally averaged properties and emphasize the competition between a wind-driven Eulerian overturning circulation and an eddy-induced bolus transport, summarized as a counteroverturning cell that relaxes isopycnals [see review by Marshall and Speer (2012) and

Corresponding author address: Andrew F. Thompson, California Institute of Technology, 1200 E. California Blvd., Pasadena, CA 91125.

E-mail: andrewt@caltech.edu references therein]. Assuming a near cancellation between wind-driven and eddy overturning cells,

$$
s \approx \frac{\tau}{\rho_{0} f K},
$$

where $\tau$ is the surface wind stress, $\rho_{0}$ is a reference density, $f$ is the Coriolis frequency, and $K$ is some estimate of the eddy buoyancy diffusivity. Note that the insensitivity of $s$ does not imply an insensitivity of the residual overturning circulation, which responds to both the amplitude and form of surface buoyancy forcing (Stewart et al. 2014). The insensitivity of the isopycnal slope to surface forcing implies an adjustment of $K$ to changes in $\tau$ or an enhancement in eddy kinetic energy (EKE) in response to a wind-driven increase in isopycnal tilt, a state sometimes referred to as "eddy saturation" (Hogg et al. 2008). Idealized, zonally symmetric models provide support for the relative insensitivity of $s$ to changes in $\tau$ (Abernathey et al. 2011; Stewart and 
Thompson 2013). Hydrographic observations also suggest changes to isopycnal slope in the ACC have been minimal over recent decades (Böning et al. 2008).

An important feature missing from residual-mean models is the representation of the ACC's complex frontal structure (Hughes and Ash 2001; Marshall et al. 2006; Sokolov and Rintoul 2009). This complexity in the ACC's frontal anatomy is complemented by a striking heterogeneity in eddy characteristics (Venaille et al. 2011; Dencausse et al. 2011; Zika et al. 2013b). Fu (2009), Lu and Speer (2010), and Sallée et al. (2011) all document an enhancement of EKE and eddy diffusivities in the lee of topography. Thompson and Sallée (2012), using passive particles advected by a satellite-derived surface velocity field, link these regions to sites of enhanced crossfront transport. Naveira Garabato et al. (2011) develop theoretical arguments, first discussed in Ferrari and Nikurashin (2010), to show that ACC jets suppress meridional transport, except in regions where jets interact with topography. Using a kinematic argument, they conjecture that the interaction of transient eddies with smallscale, nonparallel structure in the mean flow, associated with standing meanders, leads to a local intensification of eddy-induced mixing across the ACC jets.

The apparent disconnect between the ACC's alongstream structure and zonally averaged theories for overturning and stratification has parallels with atmospheric storm tracks (Chang et al. 2002; Bengtsson et al. 2006; Kaspi and Schneider 2011). Adapting these results directly to the ocean is complicated, however, by the dramatic reduction in the deformation radius, which results in a scale separation between meander and eddy length scales that does not occur in the atmosphere. This scale separation was inferred from a scaling analysis by Williams et al. (2007). Williams et al. (2007) also compare atmospheric and oceanic storm tracks and find significant alongstream structure in eddy vorticity fluxes associated with major topographic features that may both accelerate and decelerate jets.

An important consideration is how the ACC achieves the balance in (1) following a change in $\tau$. These dynamics were explored in a study by Meredith and Hogg (2006), in which satellite altimetry data point to an increase in the ACC's EKE following an intensification of the surface westerlies, as measured by the southern annular mode (SAM). The EKE rise occurs with a lag of about $2 \mathrm{yr}$, which the authors identify as the time required for baroclinic eddies to extract, via baroclinic instability, available potential energy created by winddriven isopycnal tilting. Figure 1 revisits and extends the Meredith and Hogg (2006) analysis by calculating the regional time series of EKE anomalies in the Southern Ocean, derived from satellite altimetry data between
1993 and 2010. Anomalies are defined as differences from the 18-yr average EKE. Figure 1a shows a time series of basin characteristics considered by Meredith and Hogg (2006), with the SAM index overlain. A spatial map, however, indicates that anomalies peak in discrete regions associated with persistent meanders (Fig. 1c). Isolating these features (dashed lines) produces more dramatic EKE variability (Fig. 1b), especially compared to similar-sized regions outside of meanders (dashed-dotted line). The extended time series shows that correlation with the global SAM index is tenuous. This result is consistent with Gille and Kelly (1996), who showed that the amplitude of the first EOF of Southern Ocean SSH variability does not have a circumpolar or even a basin-scale trend. More recently, Dufour et al. (2012) showed that the ACC's transient eddy response to an increase in wind stress is not zonally uniform. Morrow et al. (2010) note that Southern Ocean variability may also respond to ENSO and other climate modes and provide evidence that local variations in wind stress can generate local EKE anomalies.

In this study, we attempt to link the observed insensitivity of the ACC's isopycnal slope to the notable alongstream variability in ACC properties. Using a high-resolution, eddy-resolving ocean GCM, the Ocean General Circulation Model for the Earth Simulator (OFES), described in section 2, we explore the following hypotheses:

(i) Buoyancy surfaces undergo a persistent winddriven steepening over long stretches of the ACC where eddy fluxes are weak. This steepening is counterbalanced by isopycnal relaxation across a small number of standing meanders.

(ii) Deep eddy kinetic energy and bottom speeds are elevated in the meanders and are coupled to surface variability through vorticity dynamics.

(iii) Fluctuations in meander size are dynamically related to processes that transfer momentum vertically in the water column, both eddy buoyancy fluxes and horizontal divergence, and modify the baroclinicity of the flow.

Together these results lead us to propose that a major component of the ACC's response to changes in surface forcing occurs through fluctuations, or flexing, of the ACC's dominant standing meanders. This behavior has a negative feedback that contributes to the leadingorder wind-eddy balance expressed in (1).

Section 3 characterizes eddy properties across a small number of meanders, focusing on the vertical structure of the flow. Temporal variability in the size and structure of the meanders is also considered. Section 4 presents a discussion of this discrete view of ACC dynamics, and 

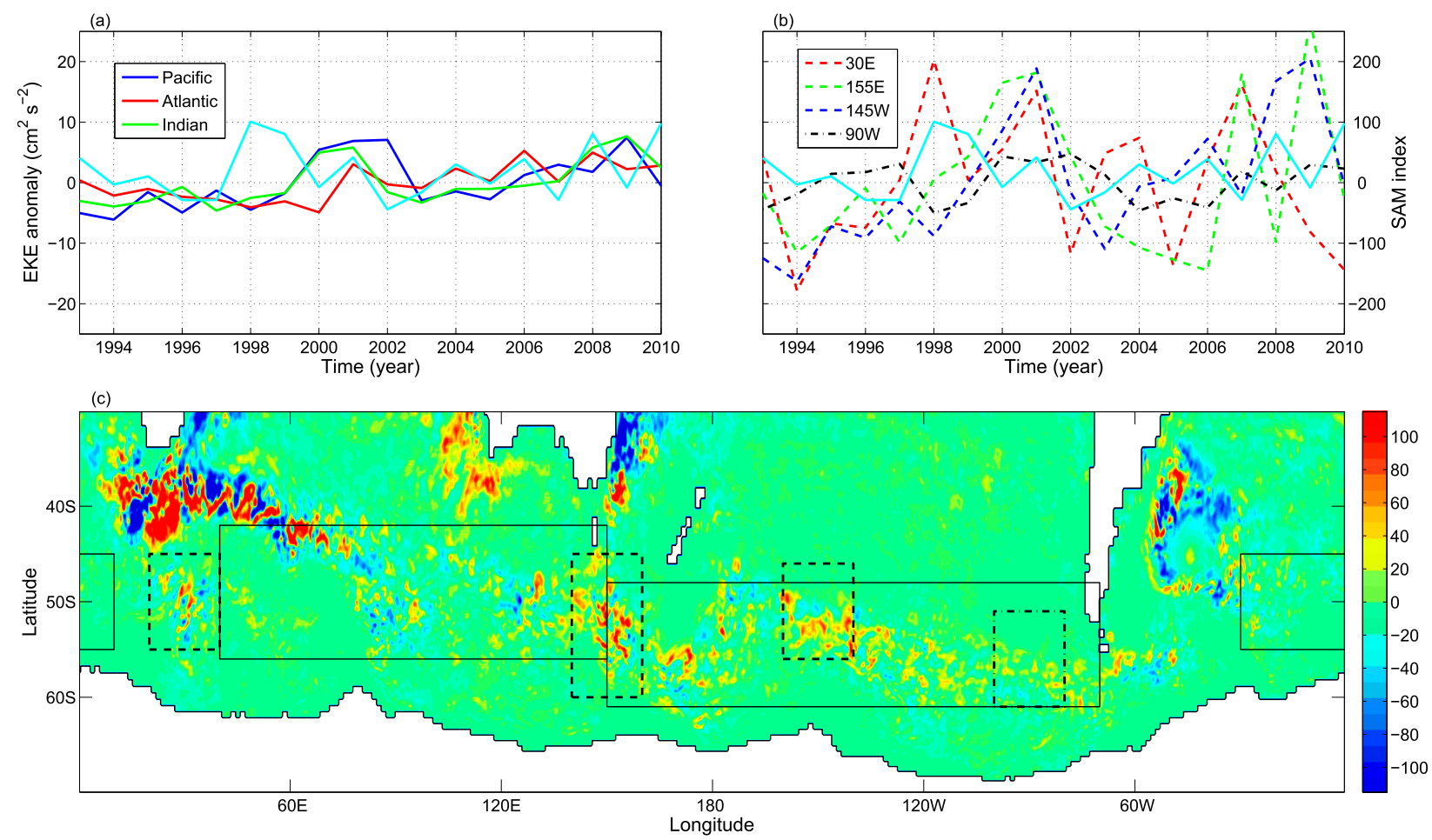

FIG. 1. (a) Time series of EKE anomalies $\left(\mathrm{cm}^{2} \mathrm{~s}^{-2}\right)$ from 1993 to 2010, calculated from satellite altimetry data, for different regions [solid lines in (c)] of the Southern Ocean (cf. Meredith and Hogg 2006, their Fig. 1). Anomalies are the difference from the 18-yr mean EKE in each region. (b) Time series of EKE anomalies $\left(\mathrm{cm}^{2} \mathrm{~s}^{-2}\right)$ for different standing meanders in the Southern Ocean [dashed lines in (c)] and for a region of similar size outside of standing meanders [dashed-dotted line in (c)]. The cyan curve in (a) and (b) shows the SAM index over this period. (c) EKE anomaly $\left(\mathrm{cm}^{2} \mathrm{~s}^{-2}\right.$ ) for 2000-02. Boxes correspond to regional averages plotted in (a) and (b).

our conclusions appear in section 5. This study does not provide a complete picture of the complex role that standing meanders play in global properties of the ACC. In particular, the relative importance of relaxation by standing meanders and transient eddies remains to be quantified. However, the dynamics discussed below highlight the need to better understand variability in the ACC's energetic standing meanders.

\section{Model data and theory}

\section{a. Ocean General Circulation Model for the Earth Simulator}

This study focuses on the spatial and temporal variability of eddies and standing meanders, with particular attention on their vertical structure. Meanders arise from flow interactions with significant topographic features. Thus, a realistic, high-resolution, primitive equation numerical model is best suited to obtain these diagnostics.

Improvements in Southern Ocean models have resulted in flows populated by many narrow, meandering smallscale jets and coherent mesoscale eddies (Hallberg and Gnanadesikan 2006; Mazloff et al. 2010). Here we use output from the $1 / 10^{\circ}$ OFES general circulation model (Masumoto et al. 2004), with emphasis placed on the dynamics governing the model output, as opposed to an exact comparison with observations of the ACC. Statistical measures from OFES, such as the distribution and amplitude of EKE, are comparable to both satellite altimetry data and other GCMs (see Thompson et al. 2010). The model includes 54 vertical levels of varying depths and realistic bathymetry. Snapshots of the temperature, salinity, and velocity fields are available every day for a period of $8 \mathrm{yr}$ following a 50 -yr spinup. Because of the vast quantity of data, we analyze snapshots obtained every third day. Time series of daily and 3-day subsampled velocity and vorticity fields have been visually inspected to ensure that high-frequency dynamics are not aliased. The model is forced with a climatological wind field, so we are unable to directly consider the response of the Southern Ocean to climatic perturbations in forcing.

\section{b. Vorticity balance}

ACC standing meanders are intricately related to the zonal transport, which is sufficiently strong that baroclinic Rossby waves are unable to travel westward 
(Hughes et al. 1998). This behavior has been linked to enhanced eddy diffusivities by Ferrari and Nikurashin (2010), among others. The strong mean flow also generates an equivalent barotropic velocity structure in which bottom form stress becomes critical for flow equilibration (Hughes and de Cuevas 2001). In regions where the wind stress is weak, the barotropic vorticity budget implies that meridional velocities, related to meanders, must be balanced by a bottom pressure torque, arising from a geostrophic flow across isobaths.

Previous efforts to ascertain the ACC vorticity budget include Hughes (2005, hereafter H05), who presents a surface budget from altimetry data under the assumption of quasigeostrophic dynamics. Chereskin et al. (2010) consider the vorticity balance from lowered acoustic Doppler current profiler (LADCP)-derived velocity data in the eastern Pacific, while Firing et al. (2011) extend the vorticity balance in the vertical using a region in the Drake Passage instrumented with current and pressure recording inverted echo sounders (CPIES; inverted echo sounders with bottom pressure and near-bottom velocity sensors). Here, we focus on the vorticity budget and its variability in pronounced standing meanders. Quasigeostrophy (QG) remains a good assumption because $\zeta / f \ll 1$ over most of the domain (not shown). From Gill (1982), the interior QG vorticity balance is

$$
\frac{\partial \zeta}{\partial t}+\mathbf{u} \cdot \nabla \zeta+\beta v-f \frac{\partial w}{\partial z}=0,
$$

where $\zeta=v_{x}-u_{y}$ and $w_{z}=-\left(u_{x}+v_{y}\right)$ by continuity; subscripts indicate partial differentiation. Assuming steady state, H05 finds a spatial anticorrelation between the advection of planetary vorticity $\beta v$ and the advection of relative vorticity $\mathbf{u} \cdot \nabla \zeta$, which is, however, sensitive to the choice of smoothing of the mean dynamic topography. H05 argues that the balance between the advection of relative vorticity and the advection of planetary vorticity implies that stationary Rossby waves are short and thus have a dominantly barotropic character. The divergence or stretching term is not calculated, but is assumed to be small. This balance between $\beta v$ and $\mathbf{u} \cdot \nabla \zeta$ holds predominantly outside of the large meanders. Using the OFES numerical output, we revisit this balance in the meanders (section $3 \mathrm{c}$ ).

\section{c. Eliassen-Palm flux}

The distribution of eddy fluxes in the ACC is also of interest, because momentum input by surface winds is transferred downward, via eddy buoyancy fluxes or interfacial form stress (Johnson and Bryden 1989), before it is removed by bottom form stress across topographic features (Munk and Palmèn 1951; Olbers et al. 2004).
We note that Ward and Hogg (2011), analyzing a fivelayer primitive equation channel model, challenge this view by showing that a rapid response of the bottom form stress, following a change in surface wind forcing, results in both a downward- (from the surface) and upward-propagating (from the bottom) baroclinic adjustment of the flow via interfacial form stress. This vertical momentum transfer requires an understanding of interior potential vorticity (PV) fluxes encapsulated by the divergence of the Eliassen-Palm (EP) tensor E (Plumb 1986). The distribution of $\mathbf{E}$ along the path of the ACC is not well documented.

In light of the zonal variability in eddy characteristics, we retain all six components of the EP tensor $\mathbf{E}=\left[\mathbf{E}_{1} ; \mathbf{E}_{2}\right]$, where

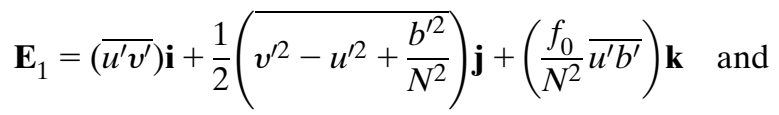

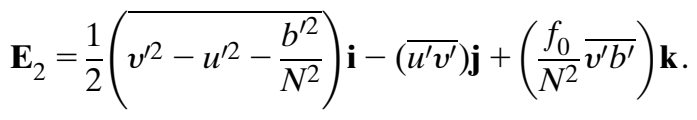

Overbars represent time averages; primed quantities are deviations from such averages; and $\mathbf{i}, \mathbf{j}$, and $\mathbf{k}$ are zonal, meridional, and vertical unit vectors. Acceleration of the zonal- and meridional-mean flows occurs in regions of divergence of $\mathbf{E}_{2}$ and $\mathbf{E}_{1}$, respectively. The divergence of these fluxes is equivalent in a QG limit to the eddy fluxes of potential vorticity:

$$
\begin{aligned}
& \overline{u^{\prime} q^{\prime}}=\nabla \cdot \mathbf{E}_{1}
\end{aligned}
$$

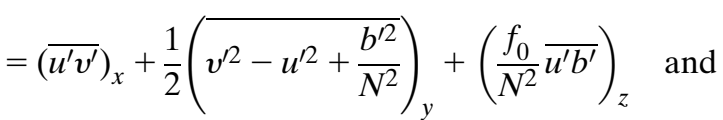

$$
\begin{aligned}
& \overline{v^{\prime} q^{\prime}}=\nabla \cdot \mathbf{E}_{2}
\end{aligned}
$$

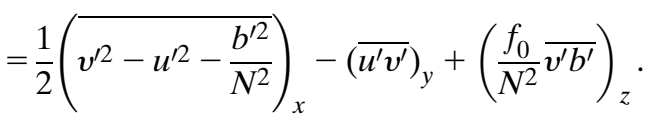

In section $3 b$, we are concerned with changes in the mean flow along the path of the meander. The eddy forcing of this alongstream mean flow is described by the cross-stream flux of QG potential vorticity $\nabla \cdot \mathcal{E}$, defined by

$$
\nabla \cdot \mathcal{E} \equiv\left(\nabla \cdot \mathbf{E}_{1}, \nabla \cdot \mathbf{E}_{2}\right) \cdot \mathbf{n}_{\perp}^{\mathrm{T}},
$$

where $\mathbf{n}_{\perp}=(-\sin \theta, \cos \theta)$ is the unit vector perpendicular to the alongstream flow direction. We show in section 3 that $\nabla \cdot \mathcal{E} \approx \partial \mathcal{E}^{z} / \partial z$, where 

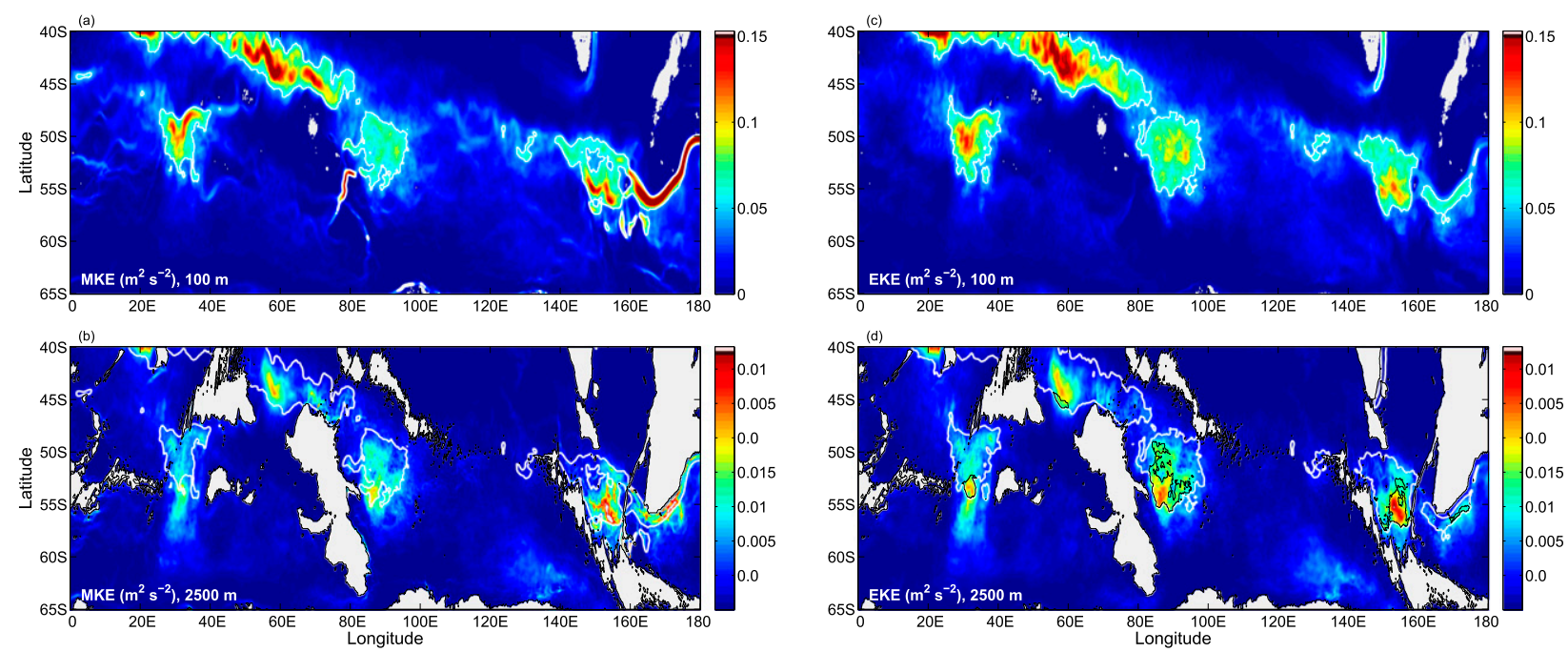

FIG. 2. Summary of OFES output. (a) MKE of the ACC's Eastern Hemisphere at $100-\mathrm{m}$ depth. The $0.05 \mathrm{~m}^{2} \mathrm{~s}^{-2}$ contour is shown in white. (b) MKE of the ACC at 2500-m depth. (c) Mean EKE at 100-m depth. The $0.05 \mathrm{~m}^{2} \mathrm{~s}^{-2}$ contour is included. (d) Mean EKE at 2500-m depth. An additional black contour indicates where the EKE at $2500 \mathrm{~m}$ is at least a tenth of the EKE at $2500 \mathrm{~m}$. Regions in gray indicate bathymetry.

$$
\mathcal{E}^{z} \equiv(\mathbf{k} \cdot \mathbf{E}) \cdot \mathbf{n}_{\perp}^{\mathrm{T}}
$$

\section{Results: The intermittent ACC}

\section{a. Meanders and stratification}

We first examine the evolution of the ACC's stratification between energetic standing meanders and regions of predominantly zonal flow. This approach is motivated by observations (Smith et al. 2010) of significant modifications in the vertical structure of the ACC across major topographic features, with a tendency toward the barotropization of the mean flow as it navigates topography.

Altimetry (Fu et al. 2010) and models (Hallberg and Gnanadesikan 2006) identify ACC meanders as sites of enhanced EKE. Figure 2 confirms that this relationship holds in OFES (only Eastern Hemisphere shown for clarity). Figure 2 a shows mean kinetic energy (MKE) and Fig. 2c shows mean EKE at $100 \mathrm{~m}$. EKE here is a deviation from an 8-yr time mean such that it contains temporal variability from both the standing meanders and transient eddies. Regions of elevated EKE are isolated downstream of significant topographic features (Fu 2009). Figures $2 \mathrm{~b}$ and $2 \mathrm{~d}$ show the subsurface distribution of these properties at a depth of $2500 \mathrm{~m}$. The subsurface distribution of EKE is not well constrained by observations. A black contour is drawn in Fig. 2d to indicate regions where both surface and subsurface values of EKE are elevated. These sites are all coincident with standing meanders. One interpretation of this distribution, which we explore next, is that mesoscale eddies make a localized contribution to the wind-eddy balance in (1).

Figure 3 (top) shows the bathymetry of the Southern Ocean from OFES; vertical lines delineate subregions considered in Figs. 3a-d. Figures $3 \mathrm{a}$ and $3 \mathrm{~b}$ consider two distinct areas: the former $\left(28^{\circ}-38^{\circ} \mathrm{E}\right)$ is a narrow sector of the ACC characterized by high EKE and dominated by a standing meander centered at $30^{\circ} \mathrm{E}$; the latter $\left(100^{\circ}-\right.$ $145^{\circ} \mathrm{E}$ ) is a broader sector of nearly zonal flow with low EKE. The contours in Figs. $3 a$ and $3 b$ indicate the change $\Delta$ in potential density $\sigma_{0}$ between downstream $\phi_{2}$ and upstream $\phi_{1}$ longitudes:

$$
\Delta \equiv \sigma_{0}\left(\phi=\phi_{2}, \xi, z\right)-\sigma_{0}\left(\phi=\phi_{1}, \xi, z\right),
$$

where $\phi$ is longitude, $\xi$ is dynamic height, and $z$ is depth. The $\sigma_{0}$ surfaces are mapped into depth-dynamic height coordinates, referenced to $2000 \mathrm{~m}$, to account for the meridional displacement of the ACC core. Arrows indicate the sense of isopycnal displacement at $1500 \mathrm{~m}$ for ease of interpretation. Figure 3 a shows a shoaling of isopycnals on the equatorward flank of the ACC consistent with a relaxation in isopycnal tilt across the meander. In contrast, $\Delta$ values of similar magnitude but with a sense indicative of a steepening of the isopycnals appear in Fig. 3b.

Figures $3 \mathrm{c}$ and $3 \mathrm{~d}$ show similar behavior in other regions of the ACC. In particular, there is the steepening of isopycnals between $120^{\circ}$ and $70^{\circ} \mathrm{W}$ across the eastern Pacific sector of the ACC. The change in density across Drake Passage is more extreme, with the isolated region now spanning $20^{\circ}$ of latitude $\left(60^{\circ}-40^{\circ} \mathrm{W}\right)$. Drake Passage 


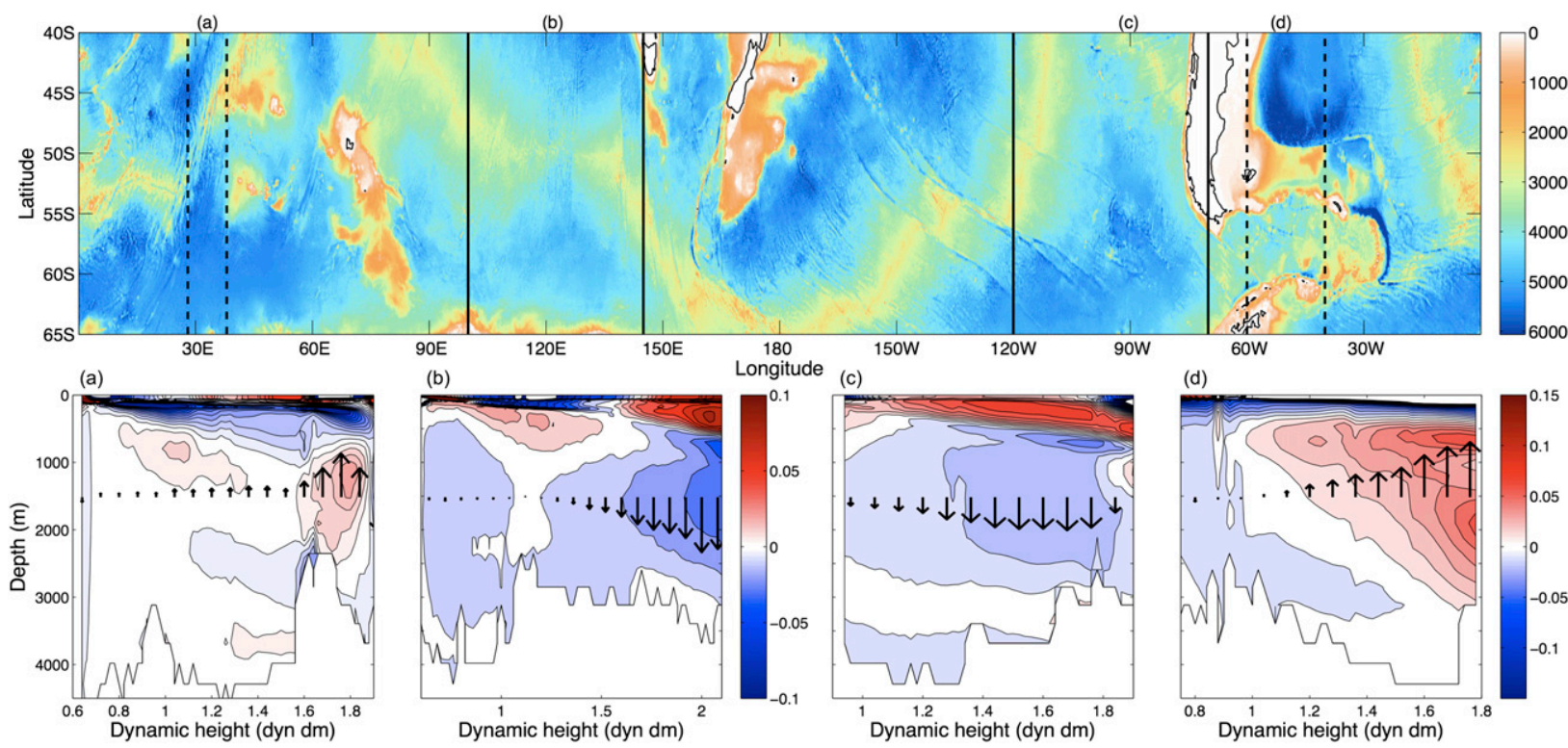

FIG. 3. (top) Depth ( $\mathrm{m})$ of the Southern Ocean in OFES. (bottom) Difference in potential density $\Delta\left(\mathrm{kg} \mathrm{m}^{-3}\right)[(9)]$ as a function of depth and dynamic height, referenced to $2000 \mathrm{~m}$, for the regions (a) $28^{\circ}-38^{\circ} \mathrm{E}$, (b) $100^{\circ}-145^{\circ} \mathrm{E}$, (c) $120^{\circ}-70^{\circ} \mathrm{W}$, and (d) $60^{\circ}-40^{\circ} \mathrm{W}$. Dynamic height increases from south to north across the ACC. Arrows are provided to show the sense of downstream isopycnal adjustment at $1500-\mathrm{m}$ depth.

is a more substantial disruption to the ACC and accommodates multiple standing meanders. This region requires further attention than there is scope for here [see review in Meredith et al. (2011)].

The residual-mean framework assumes the ACC's isopycnal slope arises from approximately equal contributions from the mean wind-driven and eddy-induced circulations. In a zonally symmetric domain, this balance applies locally at every longitude. Figures 2 and 3 show significant variability in eddy characteristics and stratification along the path of the ACC, whereas surface wind and buoyancy forcing are zonally symmetric to leading order (Large and Yeager 2009). Thus, a picture arises in which the ACC is partitioned into regions of wind-driven steepening, compensated by localized isopycnal relaxation. While this is clearly a simplified view, it represents a significant departure from the local balance implied by zonally symmetric theories of the ACC.

\section{b. Meanders and vertical structure}

We next consider the vertical structure of a typical standing meander; this feature, found at $30^{\circ} \mathrm{E}$, corresponds to the rapid relaxation of density surfaces depicted in Fig. 3a.

Figure 4a shows the mean surface buoyancy $b=$ $g \rho_{0}^{-1}\left(\rho_{0}-\rho\right), \rho_{0}=1025 \mathrm{~kg} \mathrm{~m}^{-3}$, of the meander. Upstream, the surface buoyancy contours are closely packed together, whereas immediately downstream of the meander the surface buoyancy gradient weakens, reflecting a change in subsurface density distributions (Fig. 3a). The appropriate choice of coordinate system to track flow characteristics along the path of the meander is complicated (Viebahn and Eden 2012). The meander does not coincide with an individual surface buoyancy contour, nor is it obvious whether surface properties, or properties at any single level, are the correct framework in which to "follow" the meander. Instead, we select a meander envelope, given by the 0.0045 and $0.0065 \mathrm{~m} \mathrm{~s}^{-2}$ surface buoyancy contours (Fig. 4a); properties are averaged over the meridional extent of the envelope, for example, a quantity $\chi$ averaged along the meander is given by

$$
\tilde{\chi}(\phi, t)=\frac{1}{d_{\phi}} \int_{\theta_{1}}^{\theta_{2}} \chi a d \theta
$$

where $\theta_{1}$ and $\theta_{2}$ are the latitudes of the bounding contours, $d_{\phi}$ is the meridional distance between the contours, and $a$ is Earth's radius. These contours are arbitrary, and the following results are not qualitatively dependent on the choice of contours.

Figure $4 \mathrm{~b}$ shows EKE averaged within the meander envelope. The peak in eddy kinetic energy corresponds with the crest of the meander with a striking two order of magnitude change across the meander. At depths greater than $1500 \mathrm{~m}$, the transition is abrupt. The increase and subsequent decay in deep EKE occurs over $15^{\circ}$ of longitude or approximately $1000 \mathrm{~km}$. Along-meander 

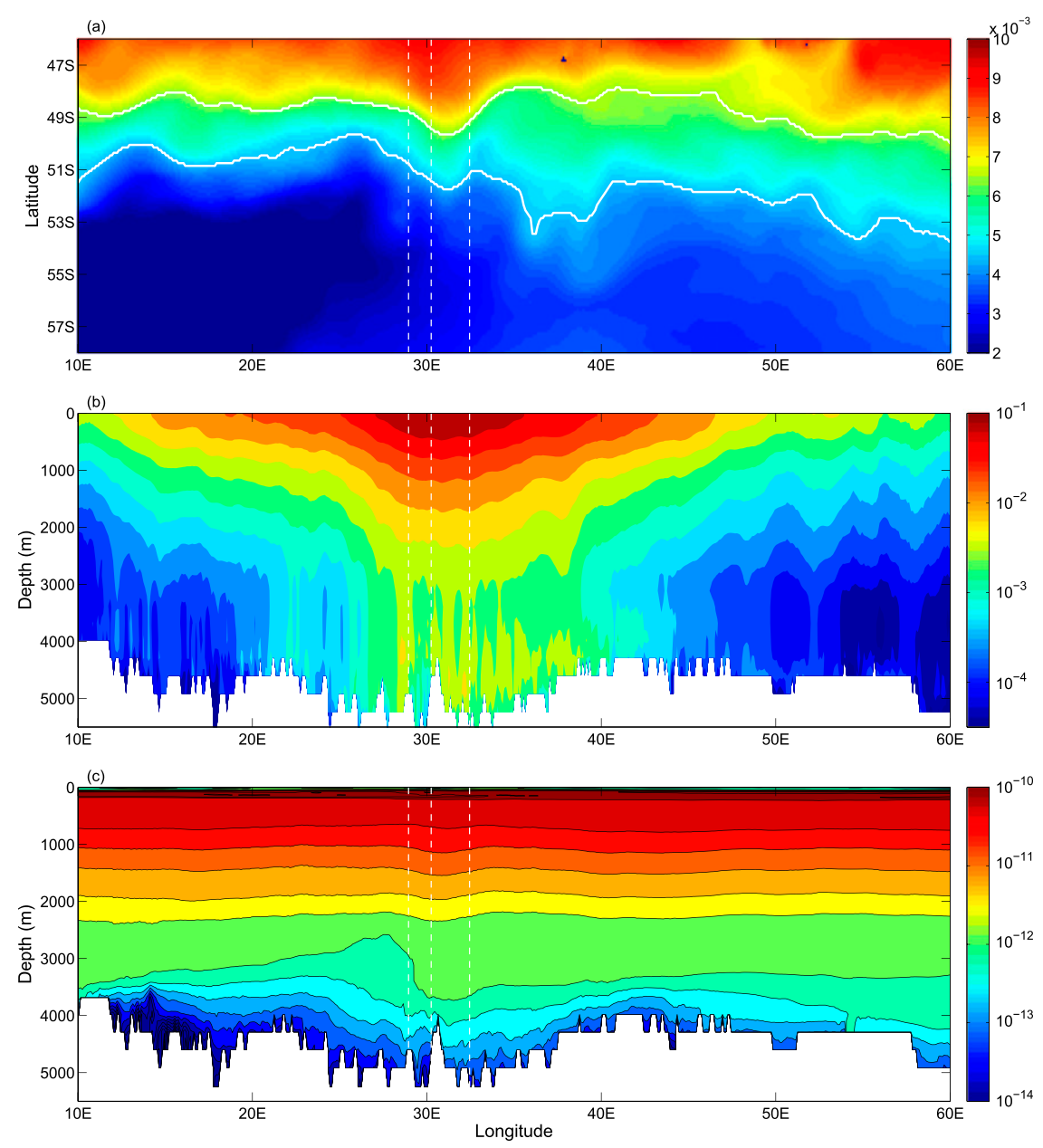

FIG. 4. (a) Surface buoyancy $\left(\mathrm{m} \mathrm{s}^{-2}\right)$ in the Atlantic sector of the ACC. White curves indicate the 0.0045 and $0.0065 \mathrm{~m} \mathrm{~s}^{-2}$ contours and provide an envelope for the meander at $30^{\circ} \mathrm{E}$. (b) EKE $\left(\mathrm{m}^{2} \mathrm{~s}^{-2}\right)$ along the path of the meander. Values represent a mean value integrated between the contours in the meridional direction; the scale is logarithmic. (c) QG PV $\left(\mathrm{s}^{-1}\right.$ ), defined in (11), integrated between the white contours in (a); the scale is logarithmic. Dashed lines are used to compare spatial variability in components of the Eliassen-Palm tensor $\mathbf{E}$ in Fig. 5.

profiles of mean KE look similar to EKE (not shown). This deep signature of EKE is important for two reasons: (i) it suggests an enhancement of subsurface eddyinduced mixing, and (ii) it provides a mechanism to locally enhance bottom form stress, if the velocities have a component directed across isobaths.

Further evidence for the enhancement of deep eddyinduced mixing is shown in Fig. 4c, which depicts potential vorticity, which is well approximated by

$$
\mathrm{PV}=f_{0} \frac{\partial}{\partial z}\left(\frac{b}{N^{2}}\right),
$$

averaged over the meander envelope. At depths in excess of $2000 \mathrm{~m}$, a bolus of homogenized PV appears concurrently with the break in the surface meander. This is further evidence that deep EKE impacts the deep stratification.

As discussed in section $2 \mathrm{c}$, acceleration of the alongstream mean flow via eddy-induced fluxes is related to the divergence of the Eliassen-Palm flux $\nabla \cdot \mathcal{E}$. Figure 5 diagnoses the full calculation of $\nabla \cdot \mathcal{E}$ from (7) as well as the approximation $\partial \mathcal{E}^{z} / \partial z[(8)]$ and the difference of the two values. A striking feature is that the vertical flux of momentum is truly localized in the standing meander.

A recurrent pattern found in the ACC standing meanders entails a divergence of $\mathcal{E}^{z}$ upstream of the meander and a deep convergence of $\mathcal{E}^{z}$ within or just downstream of the meander. This pattern is consistent 


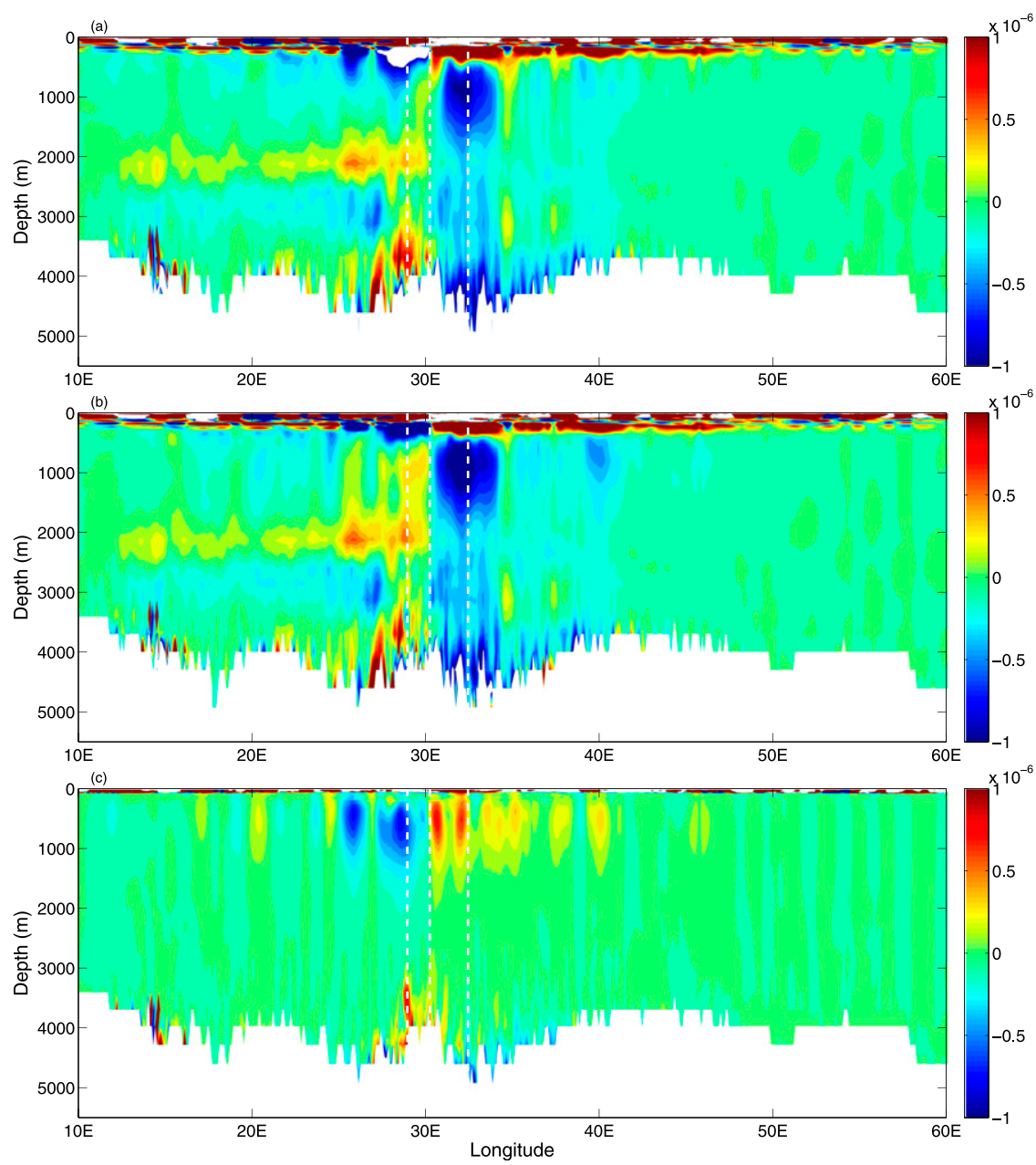

FIG. 5. (a) Eddy forcing of the alongstream flow as diagnosed by the divergence of the Eliassen-Palm vector $\nabla \cdot \mathcal{E}\left(\mathrm{m} \mathrm{s}^{-2}\right)$ defined in (7). (b) Vertical divergence of the vertical component of the Eliassen-Palm tensor $\partial \mathcal{E}^{z} / \partial z\left(\mathrm{~m} \mathrm{~s}^{-2}\right)$ defined in (8). (c) The difference between (a) and (b).

with an acceleration of the jet leading into the meanders, which agrees with the acceleration found by Williams et al. (2007). The divergent band has a vertical structure, with greater values near the surface, that implies an alongstream increase in the baroclinicity of the flow. The band of convergence, on the other hand, occurs at the site of highest EKE and is associated with a broadening of the jet and a deceleration of the mean flow. The negative values of $\mathcal{E}^{z}$ here imply a downward flux of momentum. The divergence of $\mathcal{E}^{z}$ has a vertical structure with larger amplitudes in the upper water column, thus making the flow more barotropic. The sites of maximum divergence/convergence and the transition between them are marked by white dashed lines in Figs. 4 and 5 for reference. Note that the convergence is displaced downstream of the meander center, suggesting an advection of transient eddies between sites of generation and mean flow modification (Pierrehumbert 1984; Bischoff and Thompson 2014, manuscript submitted to J. Phys. Oceanogr.).

The distributions of these diagnostics across different standing meanders are remarkably similar. Figure 6 shows the surface buoyancy, EKE, $\mathcal{E}^{z}(8)$, and $\partial \mathcal{E}^{z} / \partial z$ of other prominent standing meanders found at $155^{\circ} \mathrm{E}$ and $145^{\circ} \mathrm{W}$. Figures $6 \mathrm{c}$ and $6 \mathrm{~d}$ also present calculations of meander characteristics within a meander envelope, defined by the white contours in Fig. 6a. In each meander, $\nabla \cdot \mathcal{E} \approx \partial \mathcal{E}^{z} / \partial z$. Again, below $2000 \mathrm{~m}$, EKE is elevated within narrow bands that coincide with the location of the meander, and the distribution of the eddy potential vorticity fluxes implies a deceleration and barotropization across the meander. Figures 5 and 6 show that in each meander the reduction in baroclinicity within the meander dominates the acceleration 

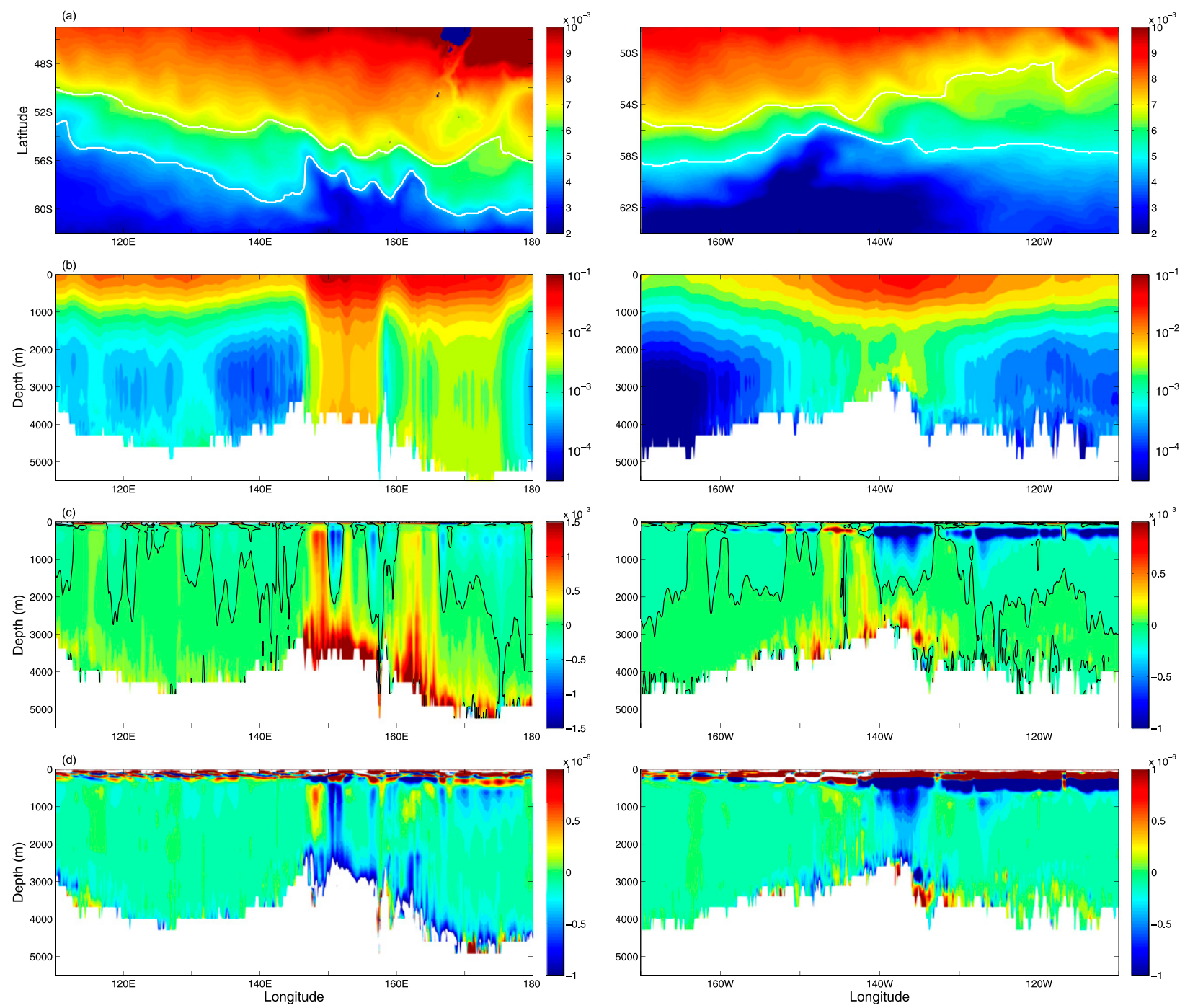

FIG. 6. Meander characteristics (left) at Macquarie Ridge and (right) over the Udintsev Fracture Zone. (a) Surface buoyancy (m s ${ }^{-2}$ ) with contours (white) used to define an envelope of the meander. (b) Vertical profile of mean EKE ( $\mathrm{m}^{2} \mathrm{~s}^{-2}$; logarithmic scale) along the path of the meander. Values are averaged between the contours in (a). (c) The $\mathcal{E}^{z}\left(\mathrm{~m}^{2} \mathrm{~s}^{-2}\right)$, see (8), averaged along the path of the meander; the zero contour is given in black. (d) The vertical divergence $\partial \mathcal{E}^{z} / \partial z\left(\mathrm{~m} \mathrm{~s}^{-2}\right)$; this term is approximately equal to the cross-stream eddy PV flux.

immediately upstream, leading to an overall barotropization of the flow in these regions.

\section{c. Meanders and vorticity balance}

From (2), the steady vorticity balance in the ocean interior implies a balance between the advection of total vorticity $(f+\zeta)$ and the stretching or divergence term $-f w_{z}$. In the barotropic vorticity balance, an incomplete cancellation between components of the advection of total vorticity results in nonzero bottom velocities (Hughes and de Cuevas 2001). H05 calculated all three terms in the steady vorticity balance [(2)] from altimetry data, but needed to apply a smoothing filter following each differentiation. This resulted in the dominant scale of the relative vorticity advection u $\cdot \nabla \zeta(300-500 \mathrm{~km})$ being comparable to meanders in the dynamic height field, and thus with the advection of planetary vorticity $\beta v$. Here, the $0.1^{\circ}$-resolution OFES allows the calculation of each term in the vorticity balance without the use of smoothing filters.

Figures $7 \mathrm{a}-\mathrm{c}$ show an 8-yr time average of the three terms in (2) for the standing meander at $150^{\circ} \mathrm{E}$ at $250-\mathrm{m}$ depth. The advection of the planetary vorticity (Fig. 7c) is the smoothest of the three terms, but is an order of magnitude smaller than the advection of relative vorticity and divergence. The divergence and advection of 

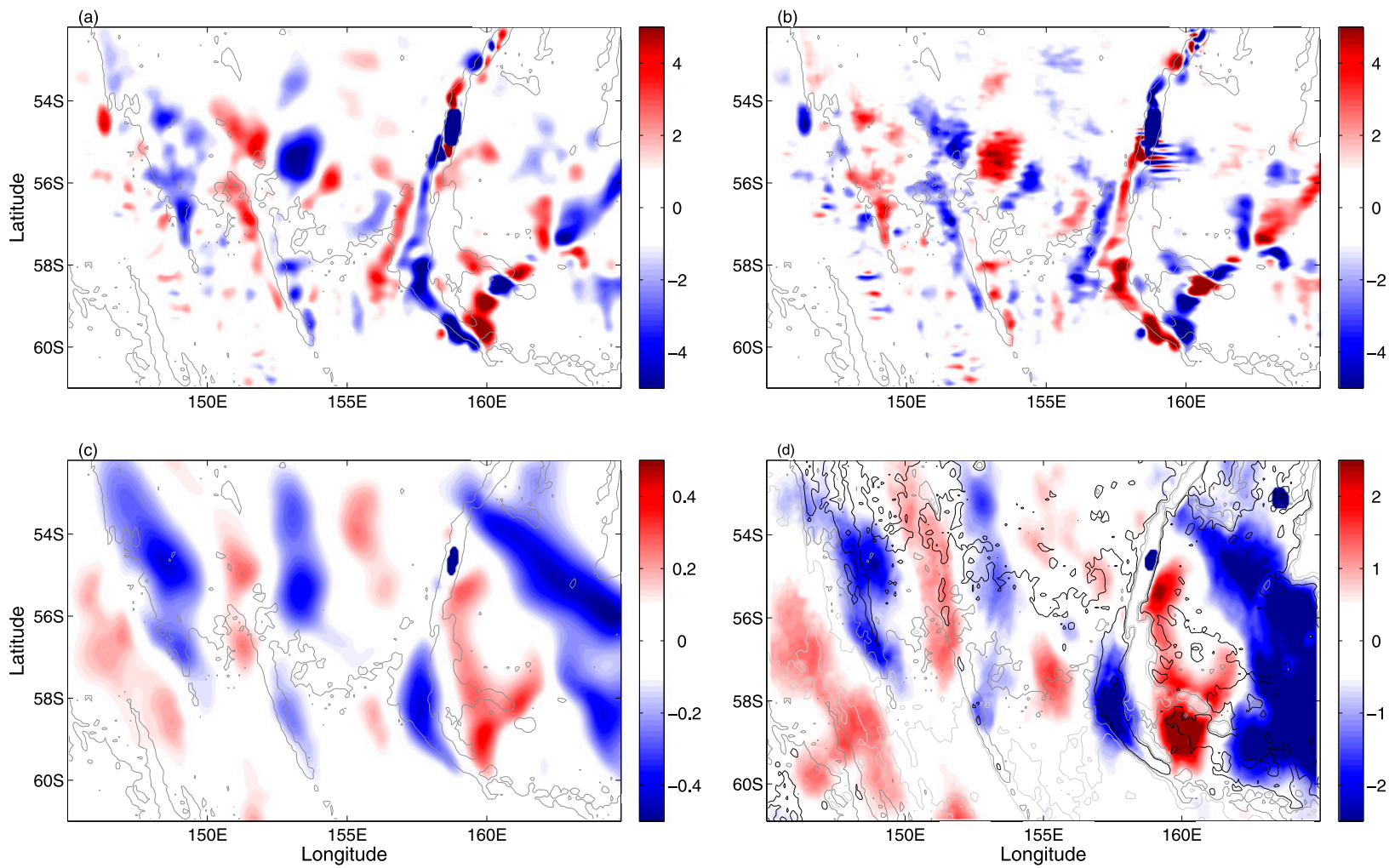

FIG. 7. The 8-yr time average of terms in the vorticity balance $[(2)]\left(10^{-11} \mathrm{~s}^{-2}\right)$ for the standing meander at $150^{\circ} \mathrm{E}$ and $250-\mathrm{m}$ depth: (a) divergence (stretching) $-f w_{z}$, (b) advection of relative vorticity $\mathbf{u} \cdot \nabla \zeta$, and (c) planetary vorticity advection $\beta v$. (d) Bottom pressure torque within the meander $\left(10^{-5} \mathrm{~N} \mathrm{~m}^{-3}\right)$. The gray contour indicates the 3500-m isobath; contours of the 4000- (black) and 3000-m (light gray) isobaths are also included in (d).

relative vorticity show smaller-scale variations and are spatially correlated. These terms also cancel to leading order with the residual having the same magnitude as the advection of planetary vorticity, but smaller spatial structure (not shown).

The balance between the advection of relative vorticity and divergence dominates throughout most of the water column, as seen in Fig. 8, which shows the spatial correlation and linear regression coefficients of the different terms in the vorticity budget at various depths. The balance between $\mathbf{u} \cdot \nabla \zeta$ and $-f w_{z}$ also holds in other major standing meanders, as shown in Fig. 9 for meanders at $30^{\circ} \mathrm{E}$ and $150^{\circ} \mathrm{W}$. The regression between these two fields in each meander is close to 1 , which is similar to H05, although we also find that correlation and regression coefficients are sensitive to the introduction of smoothing.

Any individual snapshot of either $f w_{z}$ or $\mathbf{u} \cdot \nabla \zeta$ shows considerably smaller scales than the time-averaged fields. These fields also vary coherently as the structure of the meander changes, a process suggesting an important role for Rossby waves. From inspection, the two terms are seen to have a strong correlation over short time scales.
Figure 10a summarizes this relationship by showing a time series of $\left|f w_{z}\right|$ (solid) and $|\mathbf{u} \cdot \nabla \zeta|$ (dashed) averaged over the region shown in Fig. 7. The temporal correlation coefficient between these two time series is 0.905 , with no smoothing and increases to 0.956 when a 2-month running-mean smoother is introduced. This strong temporal coherence is indicative of the small, spatial scale agreement that occurs between these terms.

In contrast, the barotropic vorticity balance occurs over larger scales. Figure $7 \mathrm{~d}$ shows the 8 -yr time-mean bottom pressure torque within the same standing meander, and Fig. 10b shows the temporal evolution as described above. A relationship between bottom pressure torque and meander amplitude might be expected because the leading-order balance of the barotropic vorticity budget is between the bottom pressure torque and advection of planetary vorticity (Hughes and de Cuevas 2001). In Fig. 10b, we plot a rough estimate of the meander amplitude, obtained from removing a linear approximation of the mean surface buoyancy across the meander and plotting the root-mean-square amplitude of the buoyancy anomalies over the 8-yr period. 

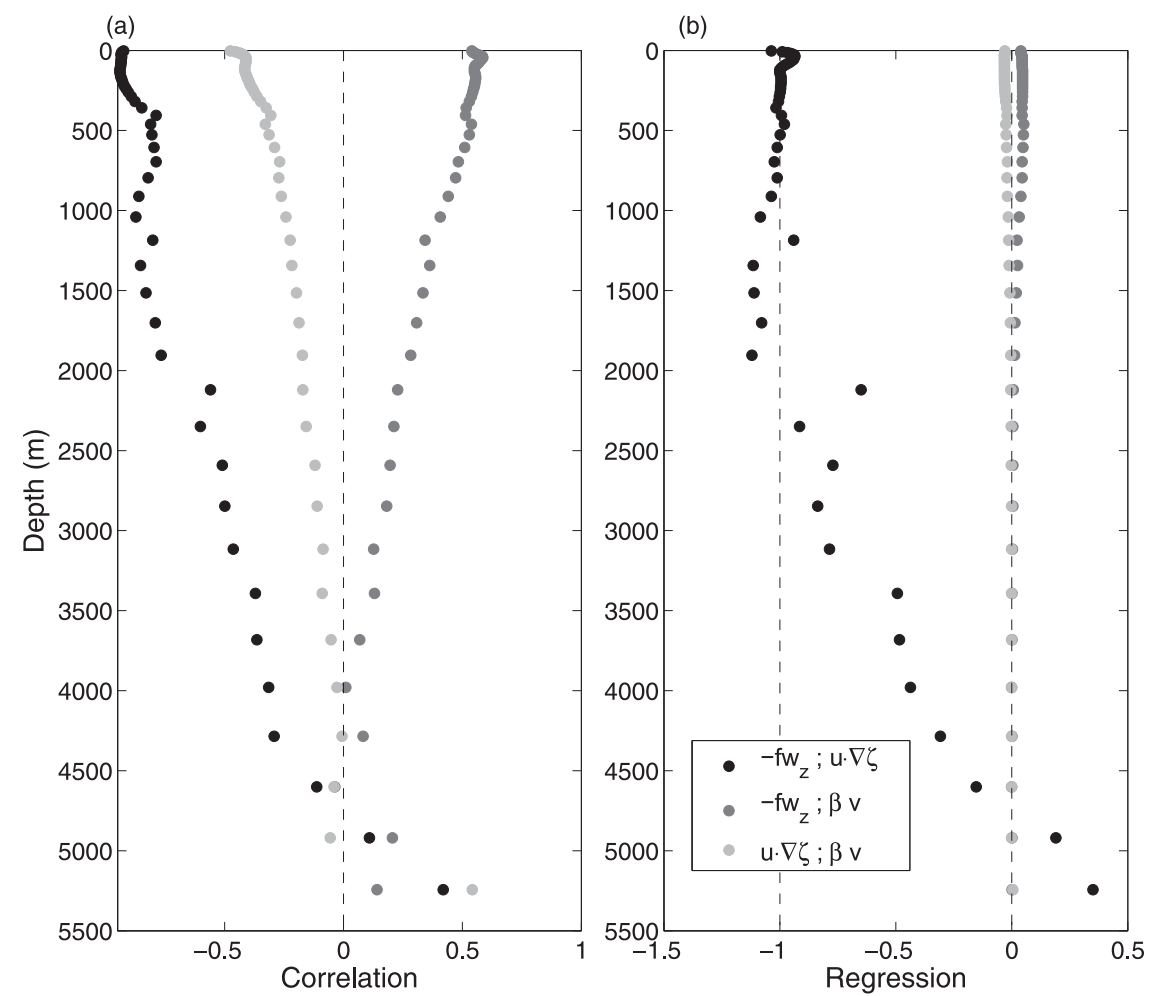

FIG. 8. (a) Spatial correlation coefficient and (b) linear regression coefficient for terms in the vorticity budget (2) as a function of depth for the standing meander at $155^{\circ} \mathrm{E}$ (Fig. 7). Colors distinguish correlations/regressions between the different terms given in the legend in (b).

The variability of the meander in the context of curvature is explored in section $3 \mathrm{~d}$.

In summary, variability in the advection of relative vorticity, related to meander dynamics, is linked to fluctuations in vertical velocities. This relationship is probed further by the inclusion of a third curve in Fig. 10a that shows a regional average of bottom speed (the lowermost complete cell at each longitude and latitude) in the meander. Bottom speed, which shows significant variations over the 8-yr time series, is strongly correlated with both the divergence (correlation coefficient $=0.913$ ) and the advection of relative vorticity (correlation coefficient $=0.892$ ); these vorticity components are calculated at $250 \mathrm{~m}$.

\section{d. Meanders and time variability}

The temporal covariance of terms in the vorticity balance motivates a consideration of how changes in the meander structure relate to eddy characteristics and follows earlier studies of standing meanders by H05 and Ochoa and Niiler (2007).

Scale separation between mesoscale eddies and the size of the meanders themselves is a distinguishing feature of ocean storm tracks (Williams et al. 2007). For example, in the vorticity budget, snapshots show a correlation between the advection of relative vorticity and divergence at scales comparable to the deformation radius $(\sim 20 \mathrm{~km})$, while the time-averaged balance and the barotropic vorticity balance is related to the meander scale $(\sim 400 \mathrm{~km})$.

A comparable scale separation in time is less apparent, however. Figures $11 \mathrm{a}-\mathrm{c}$ indicate changes to the structure of the standing meander at $155^{\circ} \mathrm{E}$ over an 8 -yr time period. Figure 11a shows the 8-yr time average of the buoyancy contours at 250-m depth for the region shown in Fig. 7-the flow is equivalent barotropic, and thus buoyancy contours have similar curvature at other depths. Figures $11 \mathrm{~b}$ and $11 \mathrm{c}$ are 2-month means of buoyancy during periods of weak and strong curvature, respectively. As a measure of curvature $\mathcal{C}(b, t)$, the length of buoyancy contours within the range $-1 \times 10^{-3}<b<5 \times 10^{-3} \mathrm{~m} \mathrm{~s}^{-2}$ are calculated. In cases where multiple contours exist, due to coherent vortices, we select the maximum contour length. These lengths are calculated for each snapshot over $8 \mathrm{yr}$, and the resulting curvature time series $\overline{\mathcal{C}}^{b}(t)$, averaged over the buoyancy range $1 \times 10^{-3}<b<2.5 \times 10^{-3} \mathrm{~m} \mathrm{~s}^{-2}$, is given by the boldface curve in Fig. 11d. Here the time series is smoothed using a 2-month running mean; periods of weak and strong curvature shown in the upper 

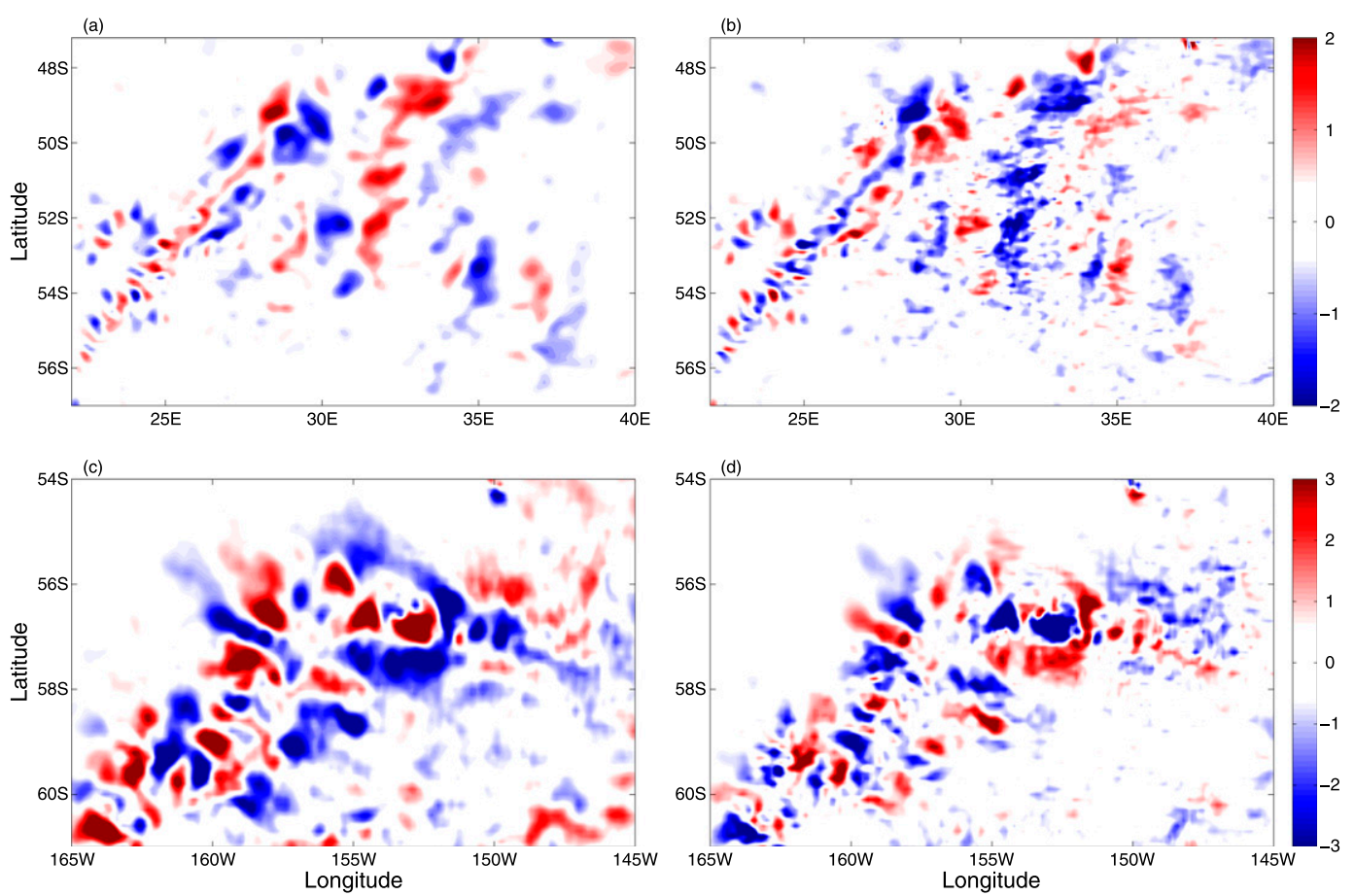

FIG. 9. (top) The 8-yr average of the (a) divergence (stretching) $-f w_{z}$ and (b) advection of relative vorticity $\mathbf{u} \cdot \nabla \zeta$ at $250 \mathrm{~m}$ at the standing meander near $30^{\circ} \mathrm{E}$. (bottom) The 8-yr average of the (c) divergence (stretching) $-f w_{z}$ and (d) advection of relative vorticity $\mathbf{u} \cdot \nabla \zeta$ at $250 \mathrm{~m}$ at the standing meander near $150^{\circ} \mathrm{W}$. Units for all terms are $10^{-11} \mathrm{~s}^{-2}$.

panels are marked by the red dashed lines. The curvature time series $\overline{\mathcal{C}}^{b}(t)$ is compared to fluctuations in the vorticity budget terms, revealing a strong temporal correlation, especially between months 20 and 90 . This agreement depends on the choice of buoyancy contour and becomes worse outside of the ACC's core. Figure 11e shows the correlation coefficient between the divergence $-f w_{z}$ and curvature $\mathcal{C}(b, t)$ time series for different values of $b$. Buoyancy contours with a correlation coefficient greater than 0.45 (dotted line) are given as boldface curves in Figs. 11a-c which explains our averaging choice for the boldface curve in Fig. 11d.

Finally, there is also a positive correlation between the time series of $\overline{\mathcal{C}}^{b}$ and meander-averaged EKE. The correlation coefficients for $\overline{\mathcal{C}}^{b}$ and EKE are 0.34 and 0.46 , where the latter value has a 2 -month running mean applied. Thus, on scales of a few months or longer, meander curvature and vorticity is tied to the generation of mesoscale variability (EKE) and even submesoscale flows (strain generation and frontogenesis), which is essential to our proposed negative feedback discussed below.

\section{Discussion}

The existing framework for understanding the ACC's equilibrated stratification (isopycnal slope) relies on a near balance between a mean and eddy overturning, where the latter is related to a zonally averaged estimate of an eddy buoyancy diffusivity. Figures 2 and 3 suggest there is a gap between this idealized picture of the ACC and the true spatial distribution of eddy generation and eddy fluxes. The largest EKE values cluster around regions where the curvature of buoyancy surfaces is large and may not be adequately described by traditional eddy parameterizations [e.g., Gent and McWilliams 1990; Ferrari and Nikurashin 2010].

Lack of high-resolution data has hampered previous studies of the ACC's vorticity balance, especially in regions of strong meandering (H05; Chereskin et al. 2010), with Firing et al. (2011) as a notable exception. These studies focus largely on the barotropic vorticity balance and emphasize a balance between the advection of relative vorticity and advection of planetary vorticity. Crucially, these studies only resolve features on the scale of the meanders themselves $(300-500 \mathrm{~km})$, while in the GCM data, the prominent spatial scales in the vorticity balance are on the order of a few tens of kilometers. It is only in the time average (Fig. 7) that the structure of the standing meander is recovered. Through the resolution of these scales, we find that at any given level the amplitude of the advection of relative vorticity and the divergence term are roughly an order of magnitude larger than the advection of planetary vorticity, a result 

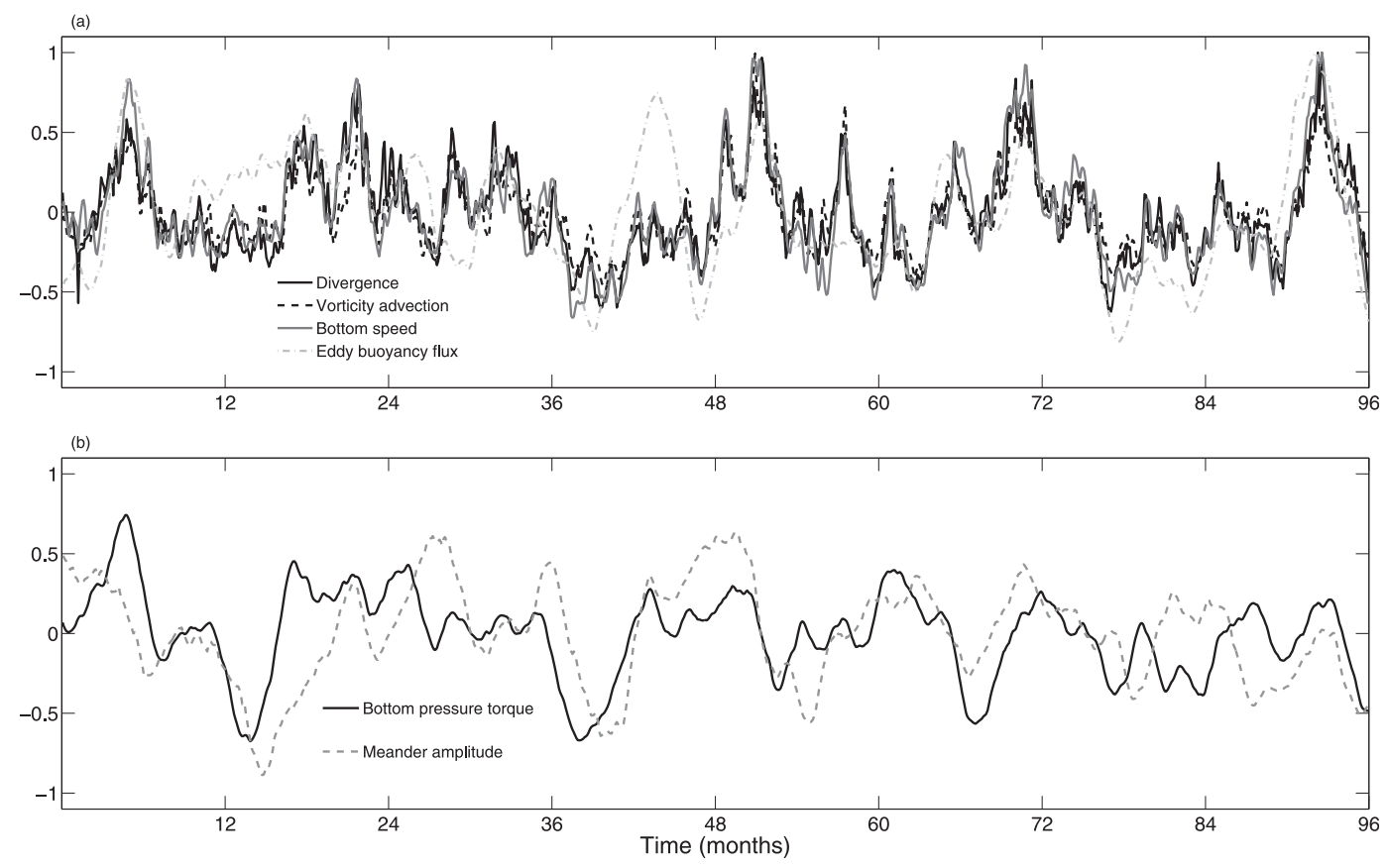

FIG. 10. (a) Time series of the magnitudes of different terms in the vorticity balance (2) for the standing meander at $155^{\circ} \mathrm{E}$ in Fig. 7 at $250-\mathrm{m}$ depth. The spatial average of the absolute magnitude of each term is calculated. The mean is removed, and the time series is normalized by the max value. Time series of the meander-averaged amplitudes of bottom speed and the meridional buoyancy flux at $250 \mathrm{~m}$ are also shown. The latter term is smoothed with a 2-month running mean. (b) Time series of the meander-averaged amplitude of bottom pressure torque; the time series is normalized as in (a). An estimate of the meander amplitude is also given (see text for description). These time series have been smoothed using a 2-month running mean.

that is confirmed in an idealized $5-\mathrm{km}$ resolution Massachusetts Institute of Technology General Circulation Model (MITgcm) channel model with topography (Bischoff and Thompson 2014, manuscript submitted to $J$. Phys. Oceanogr.). The importance of the divergence term throughout the water column (Fig. 8) suggests a role for ageostrophic vertical velocities in modifying the stratification across a standing meander. Ageostrophic vertical circulations that occur during frontogenesis (Spall 1997) are likely to be important, as Williams et al. (2007) have shown that meanders tend to be regions of frontogenesis. ${ }^{1}$ Lateral eddy buoyancy fluxes also play a role in the equilibrated stratification.

These results point to variability in the structure and eddy characteristics of standing meanders being critical to the global ACC structure. As discussed in detail in H05, standing meanders arise from the arrest of barotropic Rossby waves by the mean flow. Neglecting vertical and lateral shears, the arrested Rossby wave is

\footnotetext{
${ }^{1}$ Snapshots of the Rossby number from OFES, defined as $\zeta / f$, intermittently show magnitudes greater than 0.5 in regions of strong strain.
}

expected to exhibit a single characteristic wavelength. Waves with longer and shorter wavelengths will propagate upstream and downstream, respectively. This approach suggests that long-term changes in the shape or curvature (Fig. 11) of standing meanders are representative of changes in the mean flow. The consequences of these fluctuations are twofold.

The first effect of the meander fluctuations is somewhat tenuous, but offers a potentially new way of viewing the equilibration of the ACC. A clear signal in the diagnostics presented here, and consistent with Ward and Hogg (2011), is that changes in surface wind forcing have a rapid deep, or barotropic, response that modifies the patterns of bottom form stress or bottom pressure torque. At the ocean bottom, the pattern of these changes is related to the scale of the standing meander, not the smaller scales that govern the interior baroclinic response. An adjustment of the barotropic vorticity balance thus requires a change in the meander structure. This may occur either through an increase in meander wavelength, consistent with the expectation from the barotropic Rossby wave dispersion relation that a longer wave would be arrested by a stronger zonal-mean flow, or through an increase in meander 

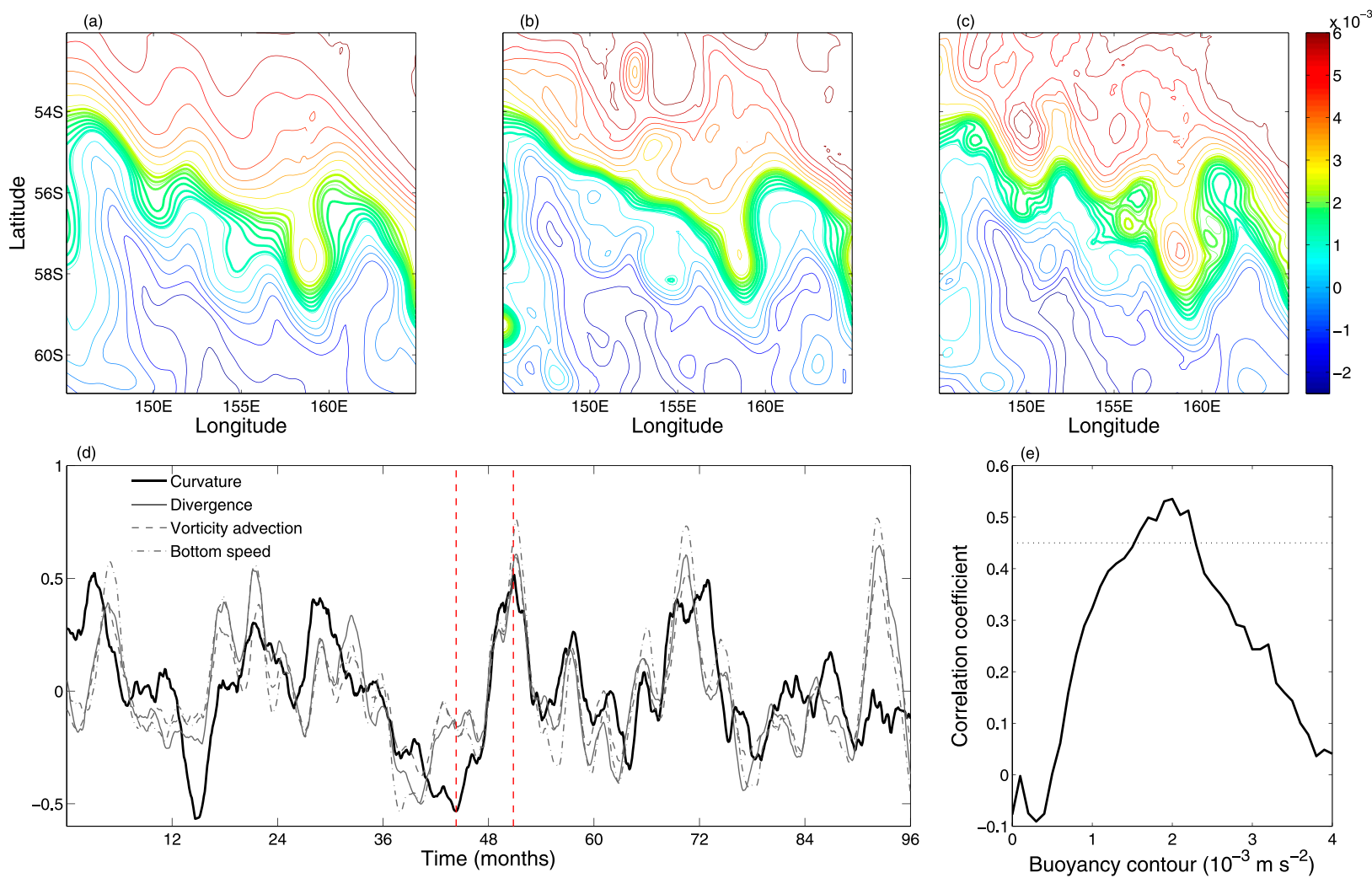

FIG. 11. Buoyancy contours at a depth of $250 \mathrm{~m}$ (a) averaged over a period of $8 \mathrm{yr}$, (b) during a period of weak curvature in year 4 , and (c) during a period of strong curvature. (d) Time series of curvature $\overline{\mathcal{C}}^{b}(t)$ (boldface curve) as measured by the mean length of the boldface buoyancy contours in (a)-(c). The time series has the mean removed and is normalized by the max amplitude; the time series is then smoothed using a 30-day running mean. The time series of the terms in Fig. 10, smoothed in the same way, are given in gray for reference. The red dashed lines indicate times of weak and strong curvature shown in (b) and (c). (e) Correlation coefficient between the divergence time series in $(\mathrm{d})$ and curvature $\mathcal{C}(b, t)$ for different buoyancy contours. The boldface curves in the upper panels correspond to values of $b$ where the correlation coefficient is greater than 0.45 .

amplitude related to an adjustment of the barotropic planetary vorticity advection. This rapid bottom response is consistent with diagnosed transports in channel models with bathymetry following a step change in wind stress: the transport rapidly increases before adjusting to a new equilibrated value (Ward and Hogg 2011). Regardless of the mechanism, this adjustment of the meander necessitates the movement of the pressure field across $f / h$ contours, modifying bottom form stress in the meander. In the model, we find a correlation between enhanced meander curvature and increased bottom speed, and we suggest that an enhancement of bottom speed may be a mechanism for enhanced dissipation either through bottom friction or more likely through the generation of lee waves (which are not resolved in the OFES). Mazloff et al. (2013) have also identified the importance of fluctuations in the position of buoyancy outcrops in the Southern Ocean, showing that a geostrophic component of the overturning circulation arises from these variations. Variability, or flexing, of key meanders will make an important contribution to this component.

The second effect is clearer and shows that meander curvature is linked to eddy characteristics in the standing meander region, diagnosed through either EKE or more complex diagnostics like the Okubo-Weiss parameter or eddy potential vorticity fluxes. The reason for this is not fully explained here, but is likely related to the enhanced instability of a nonzonal-mean flow (Smith 2007; Boland et al. 2012). This increase in eddy fluxes, however, is directly related to enhanced eddy buoyancy fluxes and the vertical transfer of momentum. ${ }^{2}$ Thus, standing meanders are key sites where changes in surface momentum forcing can be communicated rapidly throughout the water column. Fluctuations between

\footnotetext{
${ }^{2}$ Nearly stationary meanders are apparent throughout the ACC, but regions of enhanced EKE are limited to the main standing meander regions highlighted in this study.
} 
Upstream of meander:

Increased wind stress, isopycnal tilt

(a)
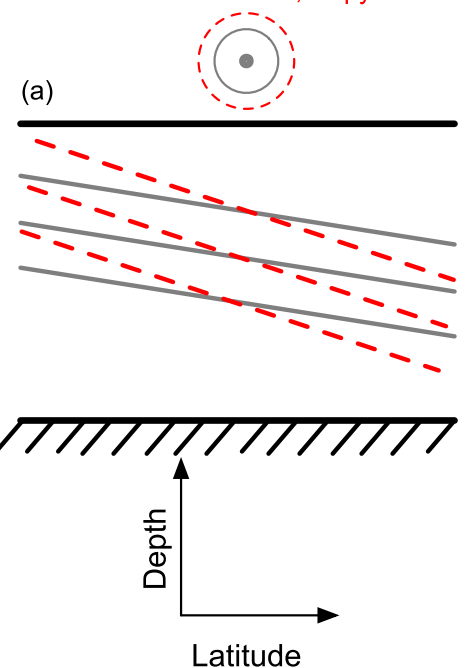

Meander plan view:

Increased meander curvature

(b)
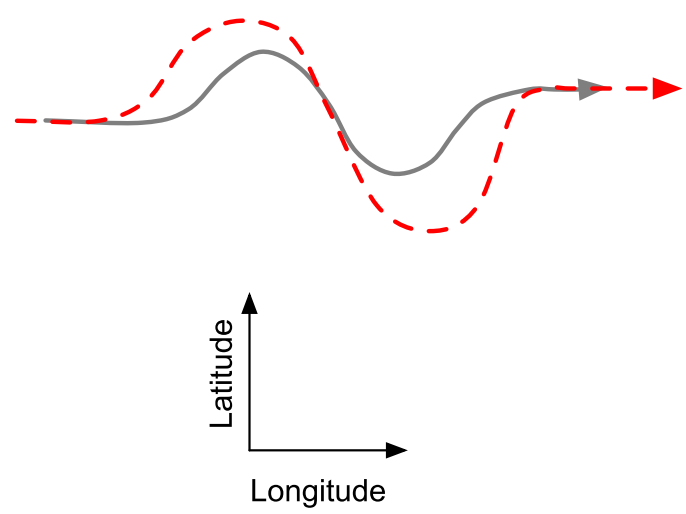

Meander vertical structure:

Enhanced vertical momentum flux, bottom speed, dissipation

(c)

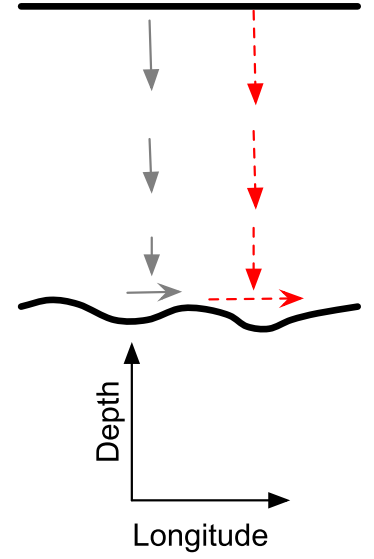

FIG. 12. Diagram of the negative feedback mechanism mediated by Southern Ocean standing meanders. Red curves and text indicate the departure from an initial state (gray curves) in response to an increase in surface wind stress. (a) Isopycnals steepen outside of regions of strong EKE, accelerating the ACC. (b) Increased zonal transport results in a reequilibration of the standing meander due to the arrest of Rossby waves with a different wavelength and change in amplitude due to a modified vorticity balance. (c) Increases in meander curvature enhance EKE, eddy buoyancy fluxes, and vertical momentum transport, which change the baroclinic structure of the meander and decelerates the mean flow. Reduction of the mean flow allows the Rossby wave to travel upstream and modify the stratification.

states of strong and weak curvature are reminiscent of the observed flipping between steered and zonal jets in idealized simulations by Thompson (2010) and may have some relation to the jet jumping of Chapman and Hogg (2013). An analysis of the Okubo-Weiss parameter (not shown) shows that meandering also enhances the strain fields, suggesting that meanders are regions where eddies are not only generated, but also torn apart by strong lateral shears, potentially leading to elevated mixing (Naveira Garabato et al. 2011; Thompson and Sallée 2012).

While this study alone is insufficient to complete the full picture, we put forward a discrete view of the ACC, motivated by the enhanced variability in a small number of standing meanders (Fig. 1). In this view, the equilibrated structure of the ACC is maintained by fluctuations in these standing meanders. The fluctuations are a combined response of arrested Rossby waves and the barotropic vorticity balance to changes in the mean flow. Figure 12 provides a diagram of this feedback mechanism. An intensification of surface westerlies steepens isopycnals and accelerates the ACC, especially upstream of meanders where EKE is relatively weak (Fig. 12a). The increased zonal transport of the ACC then results in a change in the Rossby waves that are arrested by the mean flow, specifically longer wavelengths; increases in curvature are also expected as the flow moves toward a new steady vorticity balance (Fig. 12b). Enhanced curvature leads to increased EKE and lateral eddy buoyancy fluxes, the latter being responsible for vertical momentum transport and the adjustment of the baroclinic structure of the meander (Fig. 12c). Furthermore, the standing meander sites we identify are coincident with regions of enhanced conversion of geostrophic flow into internal lee waves, as identified in recent maps by Nikurashin and Ferrari (2011) and Scott et al. (2011) and observations by Waterman et al. (2013). Most importantly, this work offers a physical mechanism that resonates with recent findings (Dufour et al. 2012; Zika et al. 2013a) that local standing meanders may provide the strongest control over the ACC's overturning. We acknowledge that a "meander only" equilibration is likely an extreme view of the ACC, and the relative importance of relaxation occurring in standing meanders and that by transient mesoscale eddies distributed throughout the ACC requires further examination.

Using ship-based and Argo hydrographic data, Böning et al. (2008) show that the ACC's mean isopycnal slope has changed little over the past two decades, despite significant changes in wind stress as measured by the SAM index. Eddy saturation was suggested as a potential explanation for this behavior. However, Munday et al. (2013) have argued that the relevant time scale for the ACC to adjust in the classical residual overturning framework is on the order of many tens of decades, due 
to the equilibration of the large basins to the north of the Southern Ocean to a new stratification. The localized response to changes in surface forcing, through the adjustment of Rossby waves and curvature discussed here, may provide a mechanism for a faster mode of equilibration to wind forcing, especially if large isopycnal excursions are limited to narrow regions around standing meanders. Finally, much of the interest in understanding the ACC's response to changes in wind stress is the potential for this mechanism to explain variations in the structure and rate of the meridional overturning circulation, through modification of isopycnal outcropping and surface buoyancy forcing, across major climatic transitions (Lynch-Stieglitz et al. 2007). It is worth noting that these standing meanders are determined by topography, and thus their location is likely to remain fixed over climatic time scales, while their structure may respond to changes in the strength of the ACC or in the spatial distribution of surface forcings. An interesting open question is the degree to which local variations in the wind stress impact Southern Ocean stratification and overturning (Zika et al. 2013a).

\section{Conclusions}

Spatial variations of the ACC's EKE distribution reflects significant alongstream changes in the dynamics that set the Southern Ocean stratification. Broadly, anomalies from the zonally averaged stratification of the ACC can be related to wide regions of isopycnal steepening where the wind-driven overturning out competes the eddy-induced overturning. These regions are typically associated with near-zonal flows with established frontal jets. Eddy activity is enhanced within the standing meanders, where isopycnal slopes relax dramatically. This enhancement of EKE, which may arise from the increased instability of the mean flow's nonzonal orientation, has two consequences. The first is to increase the cross-stream buoyancy flux, whose vertical divergence is related to the vertical transport of alongstream momentum. Enhancement in EKE is also linked to the enhancement of vertical stretching that balances the advection of relative vorticity in the vorticity budget. This balance holds specifically in the standing meanders and differs from previous analyses of the ACC vorticity balance.

While this balance holds over an 8-yr time average of the model output, perhaps more intriguing is the high coherence between temporal fluctuations generated by internal variability and seasonal fluctuations in the climatological winds. Each of the terms in the vorticity balance shows a strong correlation with meander curvature. As the flow has an equivalent barotropic structure, this change in meander structure impacts the advection of planetary vorticity. Changes in the mean flow are also expected to modify the wavelength of arrested barotropic Rossby waves, while a change in meander amplitude is consistent with the flow adjusting toward a barotropic vorticity balance. The vorticity balance suggests that eddy-meander dynamics provide a negative feedback between changes in the ACC zonal transport, patterns of bottom form drag, and eddyinduced vertical momentum fluxes responding to changes in meander curvature. This provides a mechanism by which eddy saturation of the ACC may arise. This mechanism is separate from, but potentially working in tandem with, relaxation by transient eddies.

Appreciation of the importance of standing meanders is found in some of the first studies that probed the dynamics of the ACC (e.g., Stevens and Ivchenko 1997). Here, the emphasis is on transient fluctuations in the meander structure having a strong control over the equilibration of the ACC's stratification. Our results have motivated a series of idealized numerical simulations (Bischoff and Thompson 2014, manuscript submitted to J. Phys. Oceanogr.) that confirm the importance of the meander response to changes in surface forcing. While this approach presents a potentially more complicated view of the ACC, with an emphasis on local dynamics rather than zonal- or streamwise-averaged properties, it also points to key regions that are critical to our understanding of the Southern Ocean's evolution over climatic time scales.

Acknowledgments. AFT gratefully acknowledges support from the National Science Foundation (OCE1235488), and ACNG support from a Philip Leverhulme Prize. Development of the ideas in this study have benefited from conversations with Ryan Abernathey, Toby Bischoff, Stuart Bishop, Chris Hughes, Kurt Polzin, Andrew Stewart, and Jan Zika. We thank Andy Hogg and an anonymous reviewer for comments that significantly improved this manuscript.

\section{REFERENCES}

Abernathey, R., J. Marshall, and D. Ferreira, 2011: The dependence of Southern Ocean meridional overturning on wind stress. J. Phys. Oceanogr., 41, 2261-2278, doi:10.1175/ JPO-D-11-023.1.

Bengtsson, L., K. I. Hodges, and E. Roeckner, 2006: Storm tracks and climate change. J. Climate, 19, 3518-3543, doi:10.1175/ JCLI3815.1.

Boland, E. J. D., A. F. Thompson, E. Shuckburgh, and P. H. Haynes, 2012: The formation of nonzonal jets over sloped topography. J. Phys. Oceanogr., 42, 1635-1651, doi:10.1175/ JPO-D-11-0152.1.

Böning, C. W., A. Dispert, M. Visbeck, S. R. Rintoul, and F. U. Schwarzkopf, 2008: The response of the Antarctic Circumpolar 
Current to recent climate change. Nat. Geosci., 1, 864-869, doi:10.1038/ngeo362.

Chang, E. K. M., S. Lee, and K. L. Swanson, 2002: Storm track dynamics. J. Climate, 15, 2163-2183, doi:10.1175/ 1520-0442(2002)015<02163:STD>2.0.CO;2.

Chapman, C. C., and A. M. Hogg, 2013: Jet jumping: Lowfrequency variability in the Southern Ocean. J. Phys. Oceanogr., 43, 990-1003, doi:10.1175/JPO-D-12-0123.1.

Chereskin, T. K., L. D. Talley, and B. M. Sloyan, 2010: Nonlinear vorticity balance of the Subantarctic Front in the southeast Pacific. J. Geophys. Res., 115, C06026, doi:10.1029/2009JC005611.

Dencausse, G., M. Arhan, and S. Speich, 2011: Is there a continuous Subtropical Front south of Africa? J. Geophys. Res., 116, C02027, doi:10.1029/2010JC006587.

Dufour, C. O., J. Le Sommer, J. D. Zika, M. Gehlen, J. C. Orr, P. Mathiot, and B. Barnier, 2012: Standing and transient eddies in the response of the Southern Ocean meridional overturning to the southern annular mode. J. Climate, 25, 6958-6974, doi:10.1175/JCLI-D-11-00309.1.

Ferrari, R., and M. Nikurashin, 2010: Suppression of eddy diffusivity across jets in the Southern Ocean. J. Phys. Oceanogr., 40, 1501-1519, doi:10.1175/2010JPO4278.1.

Firing, Y. L., T. K. Chereskin, and M. R. Mazloff, 2011: Vertical structure and transport of the Antarctic Circumpolar Current in Drake Passage from direct velocity observations. J. Geophys. Res., 116, C08015, doi:10.1029/2011JC006999.

Fu, L.-L., 2009: Pattern and velocity of propagation of the global ocean eddy variability. J. Geophys. Res., 114, C11017, doi:10.1029/2009JC005349.

— D. B. Chelton, P.-Y. Le Traon, and R. Morrow, 2010: Eddy dynamics from satellite altimetry. Oceanography, 23, 14-25, doi:10.5670/oceanog.2010.02.

Gent, P. R., and J. C. McWilliams, 1990: Isopycnal mixing in ocean circulation models. J. Phys. Oceanogr., 20, 150-155, doi:10.1175/ 1520-0485(1990)020<0150:IMIOCM > 2.0.CO;2.

Gill, A. E., 1982: Atmosphere-Ocean Dynamics. Academic Press, $662 \mathrm{pp}$.

Gille, S. T., and K. A. Kelly, 1996: Scales of spatial and temporal variability in the Southern Ocean. J. Geophys. Res., 101, 87598773, doi:10.1029/96JC00203.

Hallberg, R., and A. Gnanadesikan, 2006: The role of eddies in determining the structure and response of the wind-driven Southern Hemisphere overturning: Results from the Modeling Eddies in the Southern Ocean (MESO) project. J. Phys. Oceanogr., 36, 2232-2252, doi:10.1175/JPO2980.1.

Hogg, A. M., M. P. Meredith, J. R. Blundell, and C. Wilson, 2008: Eddy heat flux in the Southern Ocean: Response to variable wind forcing. J. Climate, 21, 608-620, doi:10.1175/ 2007JCLI1925.1.

Hughes, C. W., 2005: Nonlinear vorticity balance of the Antarctic Circumpolar Current. J. Geophys. Res., 110, C11008, doi:10.1029/2004JC002753.

—- and E. R. Ash, 2001: Eddy forcing of the mean flow in the Southern Ocean. J. Geophys. Res., 106, 2713-2722, doi:10.1029/ 2000JC900332.

-_, and B. A. de Cuevas, 2001: Why western boundary currents in realistic oceans are inviscid: A link between form stress and bottom pressure torques. J. Phys. Oceanogr., 31, 2871-2885, doi:10.1175/1520-0485(2001)031<2871: WWBCIR $>2.0 . \mathrm{CO} ; 2$.

_ M. S. Jones, and S. Carnochan, 1998: Use of transient features to identify eastward currents in the Southern Ocean. J. Geophys. Res., 103, 2929-2943, doi:10.1029/97JC02442.
Johnson, G. C., and H. L. Bryden, 1989: On the size of the Antarctic Circumpolar Current. Deep-Sea Res., 36, 39-53, doi:10.1016/ 0198-0149(89)90017-4.

Kaspi, Y., and T. Schneider, 2011: Downstream self-destruction of storm tracks. J. Atmos. Sci., 68, 2459-2464, doi:10.1175/ JAS-D-10-05002.1.

Large, W. G., and S. G. Yeager, 2009: The global climatology of an interannually varying air-sea flux data set. Climate Dyn., 33, 341-364, doi:10.1007/s00382-008-0441-3.

Lu, J., and K. Speer, 2010: Topography, jets and eddy mixing in the Southern Ocean. J. Mar. Res., 68, 479-502, doi:10.1357/ 002224010794657227.

Lynch-Stieglitz, J., and Coauthors, 2007: Atlantic meridional overturning circulation during the Last Glacial Maximum. Science, 316, 66-69, doi:10.1126/science.1137127.

Marshall, J., and K. Speer, 2012: Closure of the meridional overturning circulation through Southern Ocean upwelling. Nat. Geosci., 5, 171-180, doi:10.1038/ngeo1391.

_ - E. Shuckburgh, H. Jones, and C. Hill, 2006: Estimates and implications of surface eddy diffusivity in the Southern Ocean derived from tracer transport. J. Phys. Oceanogr., 36, 18061821, doi:10.1175/JPO2949.1.

Masumoto, Y., and Coauthors, 2004: A fifty-year eddy-resolving simulation of the World Ocean-Preliminary outcomes of OFES (OGCM for the Earth Simulator). J. Earth Simul., 1, 35-56.

Mazloff, M. R., P. Heimbach, and C. Wunsch, 2010: An eddypermitting Southern Ocean state estimate. J. Phys. Oceanogr., 40, 880-899, doi:10.1175/2009JPO4236.1.

— , R. Ferrari, and T. Schneider, 2013: The force balance of the Southern Ocean meridional overturning circulation. J. Phys. Oceanogr., 43, 1193-1208, doi:10.1175/JPO-D-12-069.1.

Meredith, M. P., and A. M. Hogg, 2006: Circumpolar response of Southern Ocean eddy activity to a change in the southern annular mode. Geophys. Res. Lett., 33, L16608, doi:10.1029/ 2006 GL026499.

— Ocean at Drake Passage: Past achievements and future priorities. Rev. Geophys., 49, RG4005, doi:10.1029/2010RG000348.

Morrow, R., M. L. Ward, A. M. Hogg, and S. Pasquet, 2010: Eddy response to Southern Ocean climate modes. J. Geophys. Res., 115, C10030, doi:10.1029/2009JC005894.

Munday, D. R., H. L. Johnson, and D. P. Marshall, 2013: Eddy saturation of equilibrated circumpolar currents. J. Phys. Oceanogr., 43, 507-532, doi:10.1175/JPO-D-12-095.1.

Munk, W. H., and E. Palmèn, 1951: Note on the dynamics of the Antarctic Circumpolar Current. Tellus, 3, 53-55, doi:10.1111/ j.2153-3490.1951.tb00776.x.

Naveira Garabato, A. C., R. Ferrari, and K. L. Polzin, 2011: Eddy stirring in the Southern Ocean. J. Geophys. Res., 116, C09019, doi:10.1029/2010JC006818.

Nikurashin, M., and R. Ferrari, 2011: Global energy conversion rate from geostrophic flows into internal lee waves in the deep ocean. Geophys. Res. Lett., 38, L08610, doi:10.1029/2011GL046576.

Ochoa, J., and P. P. Niiler, 2007: Vertical vorticity balance in meanders downstream the Agulhas retroflection. J. Phys. Oceanogr., 37, 1740-1744, doi:10.1175/JPO3064.1.

Olbers, D., D. Borowski, C. Völker, and J.-O. Wölff, 2004: The dynamical balance, transport and circulation of the Antarctic Circumpolar Current. Antarct. Sci., 16, 439-470, doi:10.1017/ S0954102004002251.

Pierrehumbert, R. T., 1984: Local and global baroclinic instability of zonally varying flow. J. Atmos. Sci., 41, 2141-2162, doi:10.1175/1520-0469(1984)041<2141:LAGBIO>2.0.CO;2. 
Plumb, R. A., 1986: Three-dimensional propagation of transient quasi-geostrophic eddies and its relationship with the eddy forcing of the time-mean flow. J. Atmos. Sci., 43, 1657-1678, doi:10.1175/1520-0469(1986)043<1657:TDPOTQ>2.0.CO;2.

Sallée, J. B., K. Speer, and S. R. Rintoul, 2011: Mean-flow and topography control on surface eddy-mixing in the Southern Ocean. J. Mar. Res., 69, 753-777, doi:10.1357/002224011799849408.

Scott, R. B., J. A. Goff, A. C. Naveira Garabato, and A. J. G. Nurser, 2011: Global rate and spectral characteristics of internal gravity wave generation by geostrophic flow over topography. J. Geophys. Res., 116, C09029, doi:10.1029/2011JC007005.

Smith, I. J., D. P. Stevens, K. J. Heywood, and M. P. Meredith, 2010: The flow of the Antarctic Circumpolar Current over the North Scotia Ridge. Deep-Sea Res. I, 57, 14-28, doi:10.1016/ j.dsr.2009.10.010.

Smith, K. S., 2007: Eddy amplitudes in baroclinic turbulence driven by nonzonal mean flow: Shear dispersion of potential vorticity. J. Phys. Oceanogr., 37, 1037-1050, doi:10.1175/JPO3030.1.

Sokolov, S., and S. R. Rintoul, 2009: Circumpolar structure and distribution of the Antarctic Circumpolar Current fronts: 1. Mean circumpolar paths. J. Geophys. Res., 114, C11018, doi:10.1029/2008JC005108.

Spall, M. A., 1997: Baroclinic jets in confluent flow. J. Phys. Oceanogr., 27, 1054-1071, doi:10.1175/1520-0485(1997)027<1054: $\mathrm{BJICF}>2.0 . \mathrm{CO} ; 2$.

Stevens, D. P., and V. O. Ivchenko, 1997: The zonal momentum balance in an eddy-resolving general-circulation model of the Southern Ocean. Quart. J. Roy. Meteor. Soc., 123, 929-951, doi:10.1002/qj.49712354008.

Stewart, A. L., and A. F. Thompson, 2013: Connecting Antarctic cross-slope exchange with Southern Ocean overturning. J. Phys. Oceanogr., 43, 1453-1471, doi:10.1175/JPO-D-12-0205.1.

, R. Ferrari, and A. F. Thompson, 2014: On the importance of surface forcing in conceptual models of the deep ocean. J. Phys. Oceanogr., 44, 891-899, doi:10.1175/JPO-D-13-0206.1.
Thompson, A. F., 2010: Jet formation and evolution in baroclinic turbulence with simple topography. J. Phys. Oceanogr., 40, 257-278, doi:10.1175/2009JPO4218.1.

_ and the impact on transport in the Antarctic Circumpolar Current. J. Phys. Oceanogr., 42, 956-972, doi:10.1175/ JPO-D-11-0135.1.

— , P. H. Haynes, C. Wilson, and K. J. Richards, 2010: Rapid Southern Ocean front transitions in an eddy-resolving ocean GCM. Geophys. Res. Lett., 37, L23602, doi:10.1029/ 2010 GL045386.

Venaille, A., G. K. Vallis, and K. S. Smith, 2011: Baroclinic turbulence in the ocean: Analysis with primitive equation and quasigeostrophic simulations. J. Phys. Oceanogr., 41, 16051623, doi:10.1175/JPO-D-10-05021.1.

Viebahn, J., and C. Eden, 2012: Standing eddies in the meridional overturning circulation. J. Phys. Oceanogr., 42, 1486-1508, doi:10.1175/JPO-D-11-087.1.

Ward, M. L., and A. M. Hogg, 2011: Establishment of momentum balance by form stress in a wind-driven channel. Ocean Modell., 40, 133-146, doi:10.1016/j.ocemod.2011.08.004.

Waterman, S. N., A. C. N. Garabato, and K. L. Polzin, 2013: Internal waves and turbulence in the Antarctic Circumpolar Current. J. Phys. Oceanogr., 43, 259-282, doi:10.1175/ JPO-D-11-0194.1.

Williams, R. G., C. Wilson, and C. W. Hughes, 2007: Ocean and atmosphere storm tracks: The role of eddy vorticity forcing. J. Phys. Oceanogr., 37, 2267-2289, doi:10.1175/JPO3120.1.

Zika, J. D., and Coauthors, 2013a: Vertical eddy fluxes in the Southern Ocean. J. Phys. Oceanogr., 43, 941-955, doi:10.1175/ JPO-D-12-0178.1.

_ J. L. Sommer, C. Dufour, and A. C. Naveira Garabato, 2013b: Acceleration of the Antarctic Circumpolar Current by wind stress along the coast of Antarctica. J. Phys. Oceanogr., 43, 2772-2784, doi:10.1175/JPO-D-13-091.1. 